\title{
AN EXPERIMENTAL STUDY OF THE OCULAR REACTIONS OF THE INSANE FROM PHOTOGRAPHIC RECORDS.
}

\author{
BYr ALLEN ROSS DIEFENDORF, M.D., \\ Lecturer in Psychiatry in Fale University Medical School, \\ AND \\ RAYMOND DODGE, PH.D., \\ Professor of Psychology in Wesleyan University.
}

WITHIN the last few years exact knowledge of the normal movements of the eyes has made rapid advance, particularly in America, through the use of mechanical and photographic registering devices. Quantitative information is now at hand with respect to the anglevelocity $[2,3,9]^{1}$ and the path of the line of regard during rapid eyewovements $[4-6,8,10-16],{ }^{1}$ the accuracy, stability and variability of fixa-. tion under a considerable variety of circumstances $[4,6,8,10-15]{ }^{1}$ the ocular reaction-time [8], ${ }^{1}$ and the peculiar modifications of eye-movements which constitute short-lived motor habits [5], ${ }^{1}$ pursuit movements $[7],{ }^{1}$ co-ordinate compensatory eye-movements $[7,8],{ }^{1}$ and the unovements of convergence [12]. ${ }^{1}$

The ease with which the photographic technique can be adapted to a wide variety of experimental requirements, together with certain peculiarities of the eye-movements themselves, led the writers to believe that a comparative study of the eye-movements of normal and insane persons might be made a fruitful contribution to our experimental knowledge of the reactions of the insane.

Such a comparative study might well find its basis in any of a large variety of experimental data. The present investigation was limited to three main problems, which were relatively clear to us, and to meet which we framed our technique.

The difficulties in any experimental study of normal psycho-physical processes are serious enough, even though one may rely on the highest

'Numbers 1 to 16 refer to the bibliography at the end of the paper (pp: 48S, 489). 
degree of intelligent coopperation on the part of the subject. In the study of abnormal mental life, additional difficulties arise from the very nature of the object of investigation, in direct proportion to its variation from the normal. As Kraepelin cogently observes, lack of comprehension of the experimental test, lack of ability to execute it, lack of interest, coöperation, and of endurance, all conspire to increase the task of the experimenter and to modify the value of his results. The consequent demand for trustworthy experimental methods, which, without too complicated technique or too unusual demands on the patient, shall yield quantitative information of significant variations from normal reactions, voices at once the need and the embarrassment of experimental psychiatry. These demands are met in part at least by the reactions of the eyes as they are known through their photographic records.

Eye-movements are neither unusual nor difficult. On the contrary, the ability to look at a bright object which appears suddenly within the field of view is one of the earliest forms of motor organization to be achieved, and it is retained long after the ability to learn new and complex forms of reaction is irretrievably lost. A patient will naturally look at a suddenly appearing object when he could learn the simplest new reaction only imperfectly and with enormous waste of time.

Moreover, while the eye-movements are intimately associated with the most complex mental activities, they are peculiarly inaccessible to subjective observation. Even the best trained observers utterly failed by introspection to discover some of the facts of eye-movements which are most conspicuous in the photographic records. For the ordinary unan, his eye-movements are usually involuntary and unconscious; they are essentially a part of the mechanical preadjustments of vision, and consciousness is concerned with the result rather than the preadjustments. They may on occasion be conscionsly initiated, but once begun they are entirely withdrawn from conscious control. This effectually prevents both arbitrary modifications and successful simulation of pathological symptoms. Moreover, relative uniformity in the previous training gives unequalled opportunity for legitimate comparison between different persons. Probably no other form of reaction is common to so many different persons in so high a state of development. The nearest competitor in this respect are the various speech functions; but gross differences of individual habits and training render generalization concerning the latter more difficult. In the eye-movements, on the other hand, we may reasonably assume almost complete identity of practice and a general high grade of efficiency. 
Finally, the technique of recording the eye-movements is relatively simple. By using the corneal reflection as the registering medium, there is absolutely no discomfort to the patient and no unusual stimulus to excite him, while the real purport of the experiment may be entirely hidden under the instructions to the patient to read exposed figures, letters, or short words, or simply to try if he can see anything at all on the black screen.

On the other hand, the photographic procedure is not without some difficulties of its own. The eyelid may droop and interfere with the recording light without parallel interference with vision. Excessive head-movements may render a considerable portion of the plate illegible or take the patient out of focus of the recording camera. But the records themselves are their own vindication, and we venture to believe that those who can appreciate the experimental difficulties of securing trustworthy comparative data will find some satisfaction in our results, and reasonable ground for expecting more of the general procedure in the future.

The unost serious limitations of our technique arise from defective vision. Just how far this may finally be found an embarrassment it is difficult to predict, since the technique permits some use of correcting glasses. The series of experiments we undertook was planned to render a considerable range of visual defects indifferent; nevertheless, in three cases we were compelled to abandon the tests because of gross refractive errors.

For both of us the most surprising feature of the experiments was the conduct of the patients during the tests. We anticipated a considerable variety of troubles, particularly from the maniacal patients, and safeguarded the npparatus in a number of entirely unnecessary ways. Naturally the worst cases of maniacal excitement were not requisitioned; but, as will later appenr in detail, we succeeded in getting excellent records from patients that in the wards appeared utterly impossible.

In only two cases did we encounter any unwillingness to participate in the tests. Something about the experiments seemed to appeal to the patients. The majority were helpful in getting into position and maintaining it. Many seemed thoroughly to enjoy the sessions; some were interested in the results; some were more sensitive than others to the blue light, as was evidenced by an occasional increased tendency to wink or to withdraw entirely from the apparatus, but the light was stopped down by blue glass so that continuous fixation produced only a mild and inoffensive after-image. Many of the patients apparently failed to notice it. 


\section{Apparatus and Technique.}

The registering device for recording the eye-reactions was a modification of the Dodge photochronograph which was designed by one of the authors, and has been used by him practically in its present form during the last five years.

As used by us it consisted of an enlarging camera of fixed length (about $5 \mathrm{ft} .[153 \mathrm{~cm}$.$] ) fitted with a Bausch and Lomb convertible$ protar, Series VIIA. The device for producing a regular motion of the sensitive photographic plate was the Dodge-Cline falling plate-holder. It consists of a light-tight box $2 \mathrm{ft} .(61 \mathrm{~cm}$.) high and $7 \mathrm{in} .(17.8 \mathrm{~cm}$.) wide, fitted with opaque slides, and capable of quick adjustment to the rear of the enlarging camera like a regular plate-holder. Within the box a movable frame, holding a 5 in. $(12.7 \mathrm{~cm}$.) by 7 in. $(17.8 \mathrm{~cm}$.) photographic plate, slides vertically on two brass tracks, so adjusted that all lateral play is taken up by springs. The movement of the sliding plate frame is accurately controlled by a simple hydrostatic device. The frame is attached to a piston-rod ending in a plunger which works in a vertical cylinder of lubricating oil. The valve of the plunger offers no resistance as the latter is raised through the oil, but it absolutely resists every effort to force it downwards. The release of the platc is effected by opening a stop-cock below the plunger, when the weight of the plate-holder forces the oil out of the cylinder at the bottom through the stop-cock, and returns it to the top of the cylinder above the plunger. The velocity of the fall is determined by the opening of the stop-cock, the viscosity of the oil, and the weight of the frame and plate.

The photographic record is made on the falling plate by photographing the image of an electric arc as it appears at the cornea of the eye. The rays of the arc light are first passed through blue glass screens to eliminate the photographically useless but physiologically disturbing rays of the lower spectrum. Those rays which are then reflected fiom the convex surface of the cornea to the camera are brought to a focus on the photographic plate by the lens of the enlarging camera.

A convenient and well-nigh necessary modification of the plateholder was introduced for the first time in the present experiments. Since one cannot presuppose much coöperation on the part of the insane in finding and maintaining the proper position of the head, it was found impossible to rely on methods of focusing that were satisfactory for normal subjects. A focusing and finding glass was consequently introduced into the falling plate-holder just below the photographic plate, and in the same plane. A system of automatic 
screens was arranged, so that during the focusing process the plate was entirely protected from light. In this way we could quietly await the opportune moment and quickly adjust the apparatus to changes in the patient's position. The apparent movement of the corneal reflection is slightly less than half the actual movement of the eyes. ${ }^{1}$.

But the actual displacement is magnified by the enlarging camera so that the total record is a continuous curve whose amplitude is about three times the actual amplitude of horizontal eye-movements, and whose height is determined by the velocity of the plate. Under the above circumstances, continuous visual fixation will be recorded as a straight vertical line on the falling plate, while any horizontal movement of the eyes will be indicated by an oblique line whose obliquity depends on the relative velocity of the horizontal and vertical components.

The difference in illumination between the corneal reflection of the arc light and its background is sufficiently marked, so that on a perfect plate there is no trace of other impressions except the record made by the corneal image of the arc light. This should appear as a fine black hair-line on an almost clear background. No limit has been reached in the number of records one plate will hold, except the purely mechanical confusion of the lines.

In our experiments the stimulus was so arranged as to begin coincidently with the beginning of the record. When the velocity of the plate is known, the duration of an eye-reaction will be given by the hoight of the vertical line of eye-fixation between the beginning of the record and the beginning of the oblique line of eye-movement. The velocity of horizontal eye-movement should be given by the obliquity of the line of eye-movement, i.e., the time, as measured by the fall of the plate, between one fixation and its successor.

Two series of records were made. One depended for its time-record on the measured length and obliquity of the lines. In the other an interruption of the recording light by a tuning-fork gave the time directly in vibrations of the tuning-fork. Notwithstanding a complex system of controls, our first records of the angle-velocity of the eyes by the former method involved such serious sources of error that we were reluctantly constrained to abandon them as practically useless. They do not appear in this report. The reaction-records, on the other hand,

\footnotetext{
1 For the mathematical theory of the movements of the corneal reflection and empirical tests of its accuracy as a measure of eye-movements, see Dodge : " Experimental Study of Visual Fixation" [8].
} 
were about equally satisfactory in both series. Each record involves in probable error of less than 0.01 second.

In convenience of control and in general trustworthiness the tuningfork interruption of the recording light is a decided advantage. It was arranged as follows:-

An arc light, with horizontal upper carbon, was mounted on a heavy optical bench behind a large condensing lens. In front of this lens, and at the point where the latter brought the rays of the arc light to in

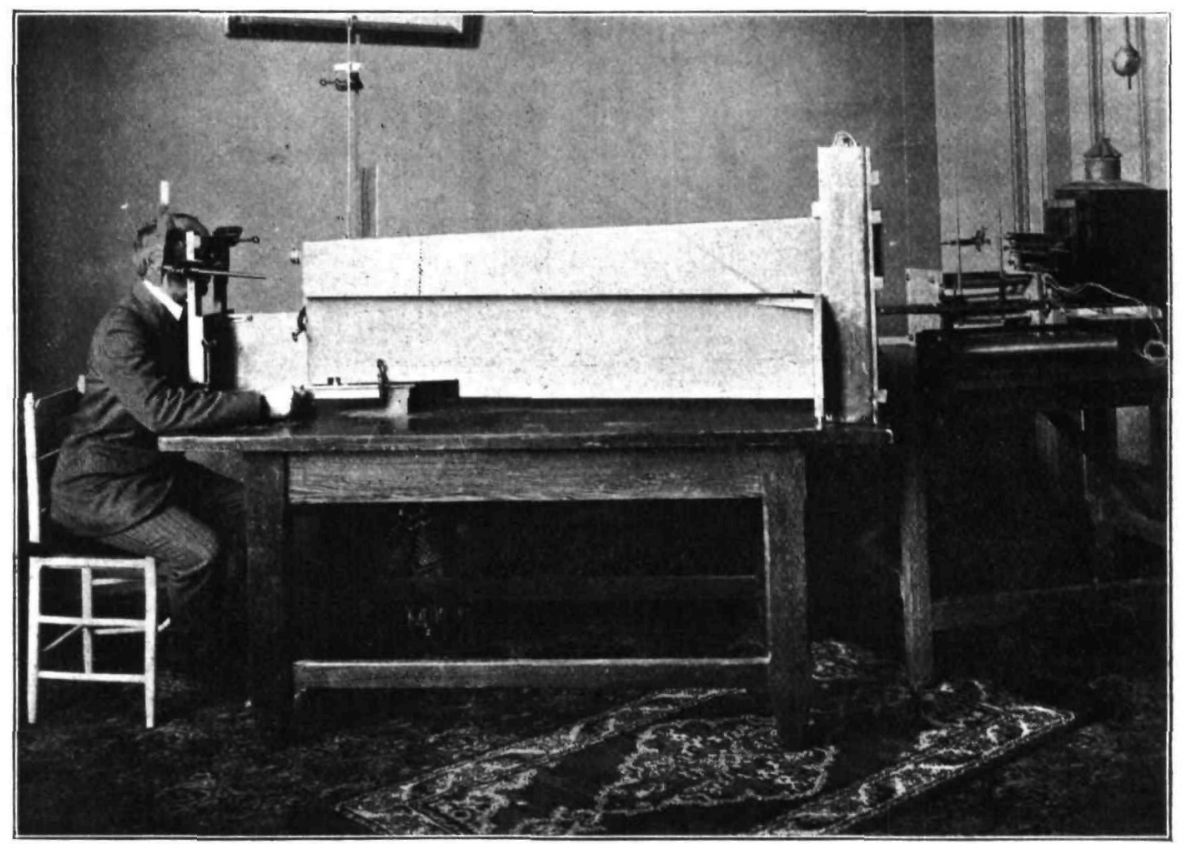

Fia. 1.

The Dodge Photochronograph.

focus, was placed an opaque screen with an opening which was so shaped and oriented that at each vibration of an electric tuning-fork (a tested Koenig tuning-fork of 100.12 c.-p. per second) the opening was alternately opened and closed to the passage of the light from the arc. A second smaller lens of 6 in. focus was so placed as to render the transmitted rays parallel. From the position of the subject one isolated vibration of the fork exposed the are light and cut it off again. With this interrupted light, when the tuning-fork was in continuous vibration, 
each record of the corneal reflection appeared on the slowly falling photographic plate as a line of black points or dashes. From the beginning of one dash to the beginning of the next represented a time interval of 0.01 second. The duration of any fixation or of any eye-movement could be read directly from the appropriate record in units of 0.01 second by counting the corresponding dots.

The arc light and the tuning-fork interrupter were placed in one corner of the laboratory at a distance of about $15 \mathrm{ft}$. $(459 \mathrm{~cm}$.) from the patient. The patient was seated comfortably at the apparatus just in front of the enlarging camera. His head was held as frrmly as practicable against a side-rest and a nosepiece. Further constraint seemed inadvisable. The resulting records were considerably complicated by head-movements, but our immediate interest was not a study of the spatial characteristics of the eye-movements, but rather a study of their temporal succession. For this purpose the records were unequivocal, except in a few cases. No patient was in the apparatus more than thirty minutes. Under favourable circumstances the tests occupied about fifteen minutes, including periods of relaxation. All records are for monocular vision. A black cardboard screen completely hid the unused eye. Three groups of tests were made on each patient at each sitting, and all three groups were recorded on the same plate. In this way each plate made a complete experimental record of a single patient at the time of examination. The plates were carefully numbered, and each number was entered in a permanent record against the name of the subject, with such additional notes of the clinical picture and conduct of the patient as seemed pertinent.

The experiment which we undertook included three tests for distinct but inter-related phenomena.

\section{(1) Velocity of Eie-Movements.}

(A) Theory.

The first test concerned the angle-velocity of simple reactive eyemovement. Experiments on normal individuals have shown a remarkable uniformity in the angle-velocity of similar uninterrupted eye-1novements of the same person, quite independent of direct conscious effort to move the eyes fast or slowly. There are slight variations of the two eyes, and slight variations in successive movements, but under similar circumstances these variations are relatively smali. 
The first published records of the angle-velocity of the eye-movements noted a slight but clear slowing up of a rapid succession of eye-movements toward the end of a series of ten movements. This was tentatively attributed to fatigue. A series of records taken in connexion with a hitherto unpublished study of fatigue confirmed the previous findings and justified the hypothesis that retardation of the velocity of the eye-movements is a phenomenon of fatigue.

Valuable as they undoubtedly would be, it was hardly to be expected that adequate fatigue tests could be obtained from the insane. On the other hand, it seemed plausible that the different disease processes, in so far as they affected the psychomotor processes at all, would variously affect the angle-velocity of the eye-movements. It also seemed probable that such variations in a type of movement which is equally practised for all subjects and is almost entirely removed from the effects of voluntary: caprice, would furnish exceptionally trustworthy comparative data.

Naturally, our immediate interest centred in patients suffering from maniacal-depressive insanity, where, as a matter of fact, the most marled variations from normal velocity were found, but the results of the test in other disease-processes are not without interest.

\section{(B) Experimental Conditions.}

The test for the angle-velocity of the eye-movements necessitated the experimental production of a considerable number of rapid reactive eyemovements of the first type (Dodge [7]) of approximately the same amplitude. Taking advantage of the fact that rapid eye-movements separate the fixation-pauses (or moments of clear vision) in reading, we satisfied the experimental requirement by exposing a succession of isolated numerals in two different parts of the field of regard about $25^{\circ}$ apart. The reading of one numeral by the patient was the signal for the operator to cover it and to expose another $25^{\circ}$ from the former. When the latter was read, it in turn disappeared and another was exposed where the first had been.

The eyes rarely moved through the entire $25^{\circ}$ from numeral to numeral in a single rapid eye-movement. This was entirely congruent with the known facts that practically every long eye-movement involves more or less final readjustment in the form of short corrective movements. When the object of interest is relatively obscure, like a numeral $25^{\circ}$ from the fixation-point, the normal end-corrective movements will vary from $1^{\circ}$ to $5^{\circ}$. In the great majority of cases the corrective 
movement is in the same direction as the initial movement. This indicates that the initial movement was too short. If the corrective movement was negative, or if it exceeded one-sixth of the total displacement, the record was discarded. The average main corrective movements in our accepted records is about $3^{\circ}$. This reduces the average displacement corresponding with our records to about $22^{\circ}$.

A large black screen was placed at 18 in. $(45.75 \mathrm{~cm}$.) in front of the subject, at one side of the camera. This screen was permanent and served all three experiments. It was pierced by three openings in the same horizontal line. Two openings for the exposure of objects were 8 in. $(20.4 \mathrm{~cm}$ ) apart. The middle opening for the passage of the blue recording light was $5 \frac{1}{2} \mathrm{in.}(14 \mathrm{~cm}$.) from the left hand opening and was lost in the blind spot of the right eye when the centre of the left hand opening was fixed. This arrangement with respect to the blind spot was designed to lessen distraction by the light during the preliminary focusing of the camera. A movable black cardboard screen behind the permanent fixed screen carried a series of numerals. These were so oriented that as the screen fell, step by step, the numbers were successively exposed at the appropriate openings of the fixed screen. The movements of the screen were regulated by the operator. The signal to the operator was the reading of the exposed numerals by the subject. The amplitude of each movement of the screen was automatically regulated by an appropriate escapement.

Before each series of experiments two numbers were exposed respectively in the left and right hand opening, the middle one being closed. The patient was told that other numbers would appear in the same places, and that these were to be read aloud as rapidly as possible. Foreigners were encouraged to use the most familiar language. With the initial movement of the screen the middle opening was uncovered, allowing the subdued arc light to illuminate the subject's eye. Four groups of these movement-records were taken for each subject, making, when all the lines were legible, twenty-four movements. This number was unnecessarily large, since the mean variation is regularly less than half of the unit of measurement, but a tendency to coördinate winking just at the time of eye-movements together with head-movements and interrupted eye-movements uade some of the individual records useless.

Since the illumination of the subject's eye was the condition of a photographic record, the simultaneous exposure and illumination were a mechanical guarantee that the beginning of the photographic record 
was synchronous with the appearance of the stimulus to eye-movement. This arrangement gave the chief instrumental condition for the second and third series of experiments to determine the reaction-time of the ocular movements.

\section{(c) Results.}

Table I. shows the average duration of eye-movements of $\mathrm{cr}^{\circ} .22$ for nine normals, twenty-one maniacal-depressives, in both the maniacal and depressive phases, four cases of dementia præcox of the hebephrenic type, four epileptics, six paretics and one imbecile.

Under each form of insanity the data are arranged according to the severity of the disease. The most marked cases come first. Each case is described at length under the corresponding number in the Appendix, pp. 475 to 488 . All time-values are given in $\frac{1}{100 \sigma}$ second.

\section{TABSLE I.}

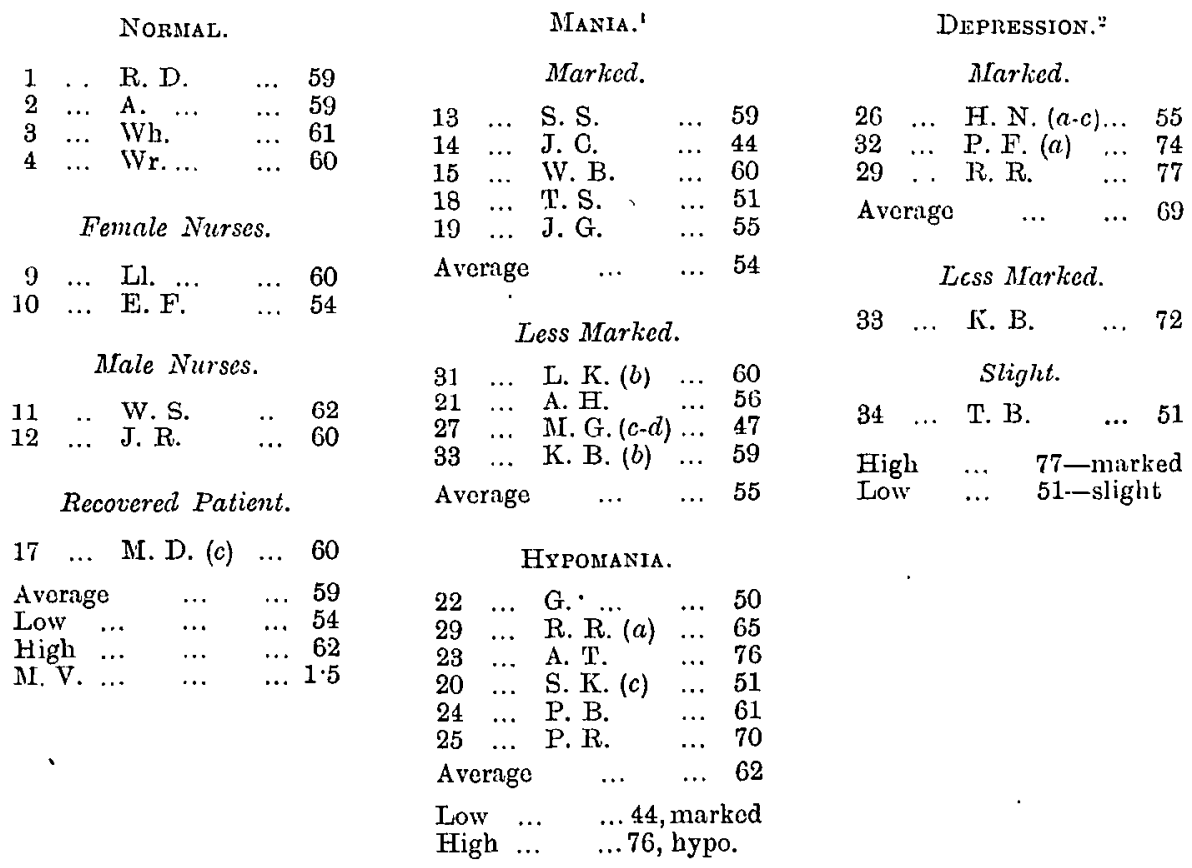


Dementia Pracox.

Marked.

\begin{tabular}{lllll}
36 & $\ldots$ & A. R. & $\ldots$ & 62 \\
37 & $\ldots$ & M. B. & $\ldots$ & 52 \\
& & & & \\
& \multicolumn{5}{c}{ Moderate. } \\
& & \\
40 & $\ldots$ & G. L. & $\ldots$ & 60 \\
41 & $\ldots$ & M. F. & $\ldots$ & 50
\end{tabular}

Slight.

$42 \quad \ldots \quad$ B. $\mathrm{MT} . \quad \ldots \quad 56$

$\begin{array}{llll}\text { Avernge } & \ldots & \ldots & 56\end{array}$
Dementia Paralytica.

Marked.

$43 \quad \ldots \quad$ D. D. $\quad \ldots \quad 54$

$\begin{array}{lllll}44 & \ldots & \text { W. H. H. } & . . & 53\end{array}$

$45 \quad$.. $\quad$ A. B. $\quad$.. 60

$47 \quad \ldots$ A. S. $\quad$.. 60

Average $\quad \ldots \quad 57$

Less Marked.

$\begin{array}{lllll}48 & \ldots & \text { J. P. E. } & \ldots & 54\end{array}$

$\begin{array}{lllll}49 & \ldots & \text { J. A. } & \ldots & 49\end{array}$

Average $\quad \ldots \quad \ldots \quad 51$
EPILeptic.

Moderate.

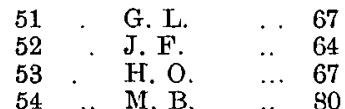

$\begin{array}{llll}\text { Averige } & \ldots & \ldots & 69\end{array}$

IMBECILE.

$57 \quad \ldots \quad$ R. $\mathbf{H}$.

60

From the preceding table (I.) it is obvious that the velocity of the eye-movements of maniacal-depressive patients does not vary exactly with the degree of depression or of maniacal excitement which they present. On the other hand, it should be noted that there is some variation even among normal persons. In any fair evaluation of our dativ, then, one must allow at the outset for some individual variations, independent of all disease. The origin of these individual variations is at present a matter of conjecture. Earlier studies $[6,9]$ demonstrated that the differences between individuals are not absolutely' constant for different angles of movement, or for the same angle of movement at different times. But these variations are relatively small, and are due, in part at least, to minor variations in the action of opposed and coöperating muscles which are not further analysed, and which may be grouped together for our purposes as chance variations. But after due allowance is made for these chance variations, the grossness of the variations in the insane and certain very obvious tendencies in different diseases and in different phases of the same disease indicate some causal interdependence with the disease itself.

While it would be injudicious to regard these tendencies as settled before our data have been materially increased, the marked variations of the extreme maniacal and the extreme depressive states may safely be regarded as characteristic. This appears not merely from Table I., but still more convincingly from the history of such cases as $26, \mathrm{H} . \mathrm{N}$, p. 481; 29, R. R., p. 482 ; and 33, K. B., p. 484 . So again both patients suffering from dementia præcox and dementia paralytica have abnormally rapid eye-movements, while the epileptics are notably long. The slow eye-movements of the extreme depressives and the quick 
eye-movements of the extreme maniacal coincide with the general psychomotor disturbances as they appear in the familiar clinical picture of these psychoses. Quantitative evidence of abnormal quickness of maniacal movements has, however, hitherto been conspicuously lacking. On

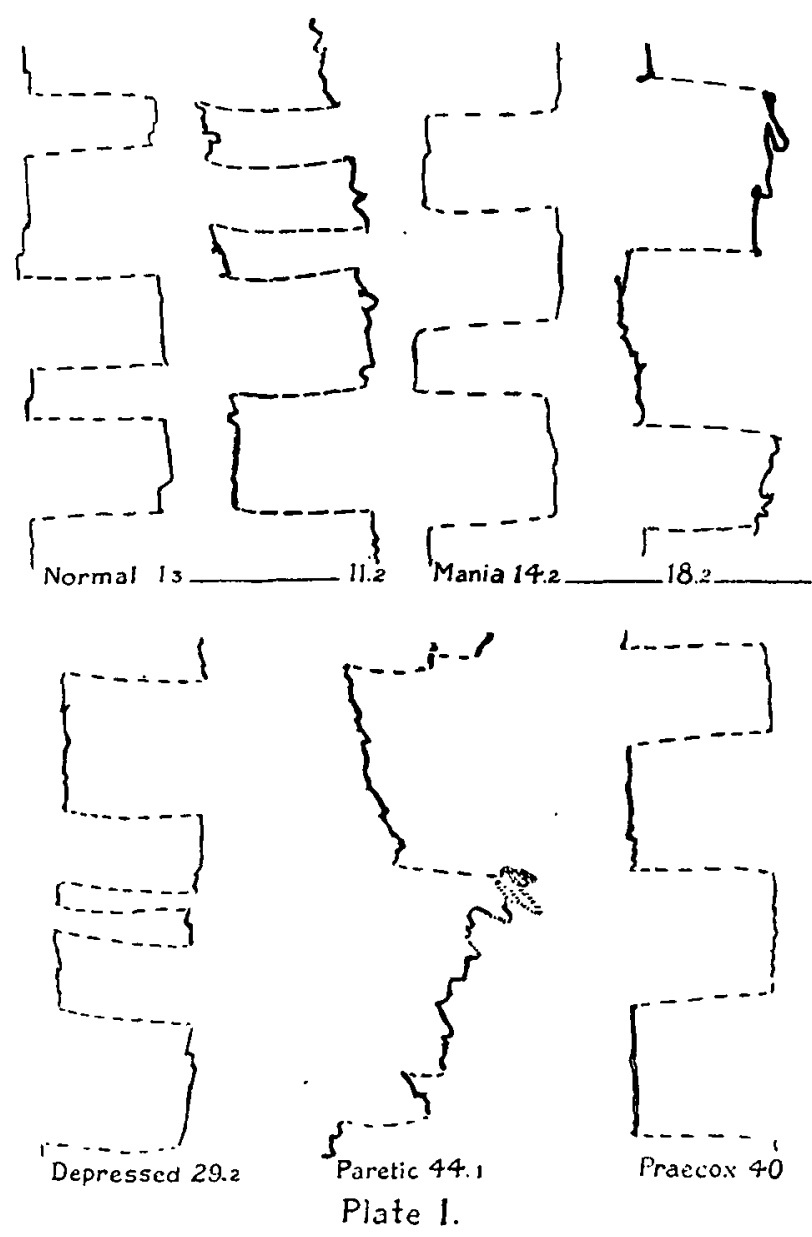

Plate $I$. is a reproduction of typical records of eye-movements. The records were projected by lantern and drawn from the projected image on a much enlarged scale. These drawings are here reproduced by process on a somewhat reduced scale. The resulting lines reproduco the original records very well, save that the dasbes are relatively fainter grey in the records. The exact shape of each dash is not accurately reproduced. In all cases which are represented in Plate I. the photographic plate was moving so stowly that the dots run together in the vertical lines, appearing as dashes only during eye-movement. The dashes represent flashes of light succeeding each other every 0.01 second. The paretic line, No. $44 \cdot 1$, is thn extreme case of head-movement and broken lines. The broken movements are typical, the head-movements less so. 
the other hand, it is again congruent with the disease-picture that the eye-movements, which we have found to be rapid, are secondary automatic acts, not those that require conscious direction and control such as have hitherto been measured; and it certainly corresponds closely with our general knowledge of the diffusion of the sensory impulses and the interaction of the higher and lower nervous centres, that these secondary automatic movements should reach their extreme velocity when the interaction of the higher nervous centres is lessened.

The slowness of the eye-movements in the depressives and in the epileptics cannot be accounted for conversely by excessive interference of the higher centres. It seems rather to be the expression of a more widespread involvement resulting in a general inefficiency of the whole psychomotor system and including not only the higher centres, which appeared to be chiefly involved in mania, but also the lower centres, the simple reflexes, and the automatic acts.

Beside the mere differences of velocity in the eye-movements, there are certain characteristic tendencies in form and accuracy of eye-movement that our technique was not designed to measure, but which may be mentioned in passing. Along with the increased velocity in the maniacal eye-movements, there is a parallel tendency to abnormal overshoots such as were first described in normal persons by E. B. Huey [3]. Depressive eye-movements are more regular and symmetrical. The eye slides up into the new position as though against a gradually increasing resistance.

The eye-movements of the grossly demented show marked inaccuracies of fixation. Advanced dementia paralytica has curious inconsequential fixations, breaking the normal eye-movements at irregular points.

(2) Ocular Reaction-Time to New Peripheral Strmuli.

The second test concerned the simple reaction of the eye in responding to a peripheral stimulus. Like the first test, the second also depended on the regular and usually wholly unconscious habit of fixing a numeral or letter one is expected to read.

\section{(A) Experimental Conditions.}

The procedure was as follows: A figure 6 was exposed in the left hand slit of the permanent screen. The subject's attention was directed 
to it with the instructions that other figures, which would appear at one side or other of the 6 , must be read as rapidly as possible. With the final warning to look sharp, the 6 suddenly dropped out of sight and 1 in. $(2.5 \mathrm{~cm}$.) to the right or left there appeared a different numeral. The exposure apparatus resembled that used in the first series of experiments. A special exposure screen was prepared so as to expose one figure (6) at the centre of the left hand opening in the permanent screen when the exposure screen occupied its primary position. A series of numbers was pasted on pieces of black cardboard which could be slipped into place either to the right or left of the 6 and just so far above it as would bring them into view by one stroke of the escapement. It only required $\frac{1}{2}$ in. $(1.25 \mathrm{~cm}$.) movement of the exposure screen to carry the 6 out of sight and to expose the new number. The movement was so rapid that it seemed like an instantaneous change. Without the appearance of motion in any direction, the one seemed to disappear and the other was in place. The same movement of the exposure screen uncovered the arc light and began the photographic record. Simply counting the dashes of which the record was composed from the beginning of the record to the beginning of the eye-movements to fix the new number gave the reaction time of the eye in 0.01 second. A similar experiment is described more in detail in Dodge's "Experimental Study of Visual Fixation" [8]. Vocal reaction to printed matter or to isolated words, such as Dodge studied, seemed inexpedient in these tests on account of gross differences in education. Four ocular reactions were taken for each subject. Unfortunately, in some cases extreme head-movements made some of the records uncertain, while winking made other records useless. These two disturbances combined materially to reduce the number of available records.

The small number of reactions for any one individual is a serious limitation to the use of our data. If we had the work to do over again, we are agreed that we should venture to increase the number of simple reactions. Our reason for limiting the number in the present tests was the consciousness that we were dealing with subjects who were abnormally susceptible to fatigue of attention. To some of them even four tests of the same kind seemed many. For the sake of comparison, we ran through a series of ten reactions each with two more tractable cases. The results show that, in these two cases at least, the smaller number did no violence to the facts. In later discussions it will appear that minimal reactions and the general variability are quite as important as the rather meaningless averages. 
(B) Results.

Table II.

Simple Ocular Reactions to Peripheral Stimuli.

(1) Nonmal.

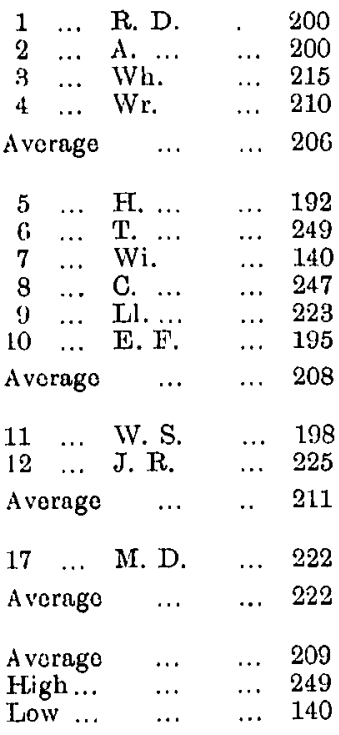

(4) Dementia Praccox.

Marked.

$$
\begin{aligned}
& \begin{array}{lllll}
36 & \ldots & \text { A. R. } & \ldots & 240
\end{array}
\end{aligned}
$$

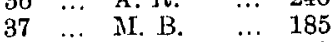

$$
\begin{aligned}
& \begin{array}{lllll}
38 & \ldots & \text { R. B. } & \ldots & 258
\end{array} \\
& \begin{array}{llll}
\text { Average } \quad \ldots & \ldots & 228
\end{array}
\end{aligned}
$$

$42 \quad \ldots \quad$ B. M. $\quad$.. 152

$\begin{array}{llll}\text { Average } & \ldots & \ldots & 222 \\ \text { High } & \ldots & \ldots & 276 \\ \text { Low } & \ldots & \ldots & 152\end{array}$

(2) Mania.

\section{Marked.}

$13 \quad \ldots \quad$ S. S. $\quad \ldots \quad 205$

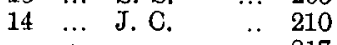

16 . 217

16 ‥ M. M. . . 225

$17 \quad \ldots \quad$ M. D. $(a)$. 250

$18 \quad \ldots \quad$ T. S. . 250

19 ... J. G. $\quad$ J. 210

$20 \quad \ldots \quad$ S. K. $(b) \ldots 229$

Average $\quad \ldots \quad \ldots 224$

\section{Less Marked.}

$31 \quad \ldots . \quad$ L. K. (c) .. 260

\begin{tabular}{|c|c|c|c|c|}
\hline 2 & $\ldots$ & G. ... & ․ & 230 \\
\hline 3 & ... & P. A. & $\ldots$ & 225 \\
\hline & $\ldots$ & S. K. (c) & & 202 \\
\hline 4 & $\ldots$ & P. B. & $\ldots$ & 170 \\
\hline & $\ldots$ & P. R. & $\ldots$ & \\
\hline & age & $\cdots$ & $\ldots$ & 11 \\
\hline & & & & \\
\hline & H & . & & \\
\hline
\end{tabular}

$21 \quad \ldots \quad$ A. H. .. 215

$\begin{array}{llll}27 & \ldots & \text { M. G. }(d) \ldots & 257\end{array}$

$\begin{array}{lllll}33 & \ldots & \text { K. B. (b) } & \ldots & 219\end{array}$

$\begin{array}{llll}\text { Average } & \ldots & \ldots & 238\end{array}$

Hypomania.

(5) Deanentia Paralytica. Marked.

$43 \quad \ldots \quad$ D. D. .. 370

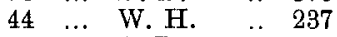

$45 \quad \ldots$ A. B. $\quad \ldots .225$

$\begin{array}{lllll}47 & \ldots & \text { A. S. } & \ldots & 237\end{array}$

Average $\quad \ldots \quad$.. 267

Loss Marled.

$\begin{array}{lllllll}48 & \ldots & \text { J. P. E. ... } & 190\end{array}$

$\begin{array}{lllll}49 & \ldots & \text { J. A. } & \ldots & 190 \\ & & \ldots & & \end{array}$

Average $\quad \ldots \quad \ldots \quad 203$

Remission.

$\left(\begin{array}{llllll}50 & \ldots & \text { F. A. }\end{array}\right.$

$\begin{array}{llll}\text { Average } & \ldots & \ldots & 246 \\ \text { High } & \ldots & \ldots & 370\end{array}$

$\begin{array}{llll}\text { How } & \ldots & \ldots & 370 \\ \text { Low } & \ldots & \ldots & 190\end{array}$
(3) Depression.

\section{Marked.}

$26 \quad \ldots \quad$ H. N. (a) ... 250

27 ... M. G. ... 295

$\begin{array}{llll}29 & \ldots & \text { R. R. (c) } \ldots & 173\end{array}$

Less Marked.

$\begin{array}{lllll}32 & \ldots & \text { P. F. } & \ldots & 379\end{array}$

Slight.

$\begin{array}{lllll}34 & \ldots & \text { T. B. } & \ldots & 293 \\ 17 & \ldots & \text { M. D. }(b) & & 204\end{array}$

Average $\quad \ldots \quad$. 266

$\begin{array}{llll}\text { High } & \ldots & \ldots & 379\end{array}$

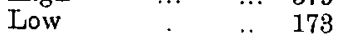

(6) Epileptic.

Moderate.

$51 \quad \ldots$ G. L. . 298

$\begin{array}{llllll}52 & \ldots & \text { J. F. } & \ldots & 228\end{array}$

$\begin{array}{llllll}53 & \ldots & \text { H. O. } & \ldots & 195\end{array}$

$\begin{array}{lllll}54 & \ldots & \text { M. B. } & \ldots & 197\end{array}$

Average $\quad \ldots \quad 229$

High . .. 298 


\section{(c) Discussion of Table II.}

The simple ocular reaction-time is long. According to our records the normal average lies above $200 \sigma$. In strict accuracy this average is undonbtedly too high, and should be reduced by a constant instrumental error of about fifteen. This error is involved in the form of the exposure of the peripheral stimulus. We have not tried to correct it, since it applies equally for all subjects, and our interest lies mainly in comparative rather than absolute time estimations. But after all corrections are made, these records agree with all the available data, and the simple ocular reaction-time is long.

One might a priori have expected that a reaction which is at once so common and apparently so necessary to the welfare of the individual in the conduct of life would be short. On the other hand, it must be noted that each ocular reaction to peripheral stimuli involves a considerable sensori-motor elaboration of the stimulus. The adequate reacting eye-movement is not only in a definite direction, but it is also of definite extent. The accuracy of the eye-movement does not now concern us, since we measure in reaction-time only the beginning of the reactive movement. But the beginning of every eye-movement is really only the initial phase of a movement of definite direction and extent. Before the eye starts, the elaboration of that particular motor impulse must be relatively complete. An accurate account of the correspondence between reaction-time and reaction-accuracy is a desideratum.

In a sense, every ocular reaction to a peripheral stimulus is not a simple reaction at all, but an individual adaptation to a change in the environment. In the past, such a reaction would have borne the misleading name of a "choice reaction." The length of the simple ocular reaction, then, is not an anomaly. It corresponds directly with the complex but automatic elaboration of the sensori-motor impulse.

Abnormal reactions may result from an indefinite number of changes within this complex sensori-motor process. This is at once the inspiration and the danger of every interpretation of complex reactions. In view of the possible complications, the relatively small mean variation for normal subjects points to a relatively stable normal oculo-motor: systematization. It emphasizes at the same time the gross variations of the insane.

The small number of per capita records forces us to consider the reactions, as we were led to consider the velocity of movement by groups rather than by individuals. Furthermore, we will again limit 
our generalizations to such gross variations as are inexplicable on the basis of chance variations.

The most conspicuous comparative feature of the results is the abnormally long reactions of the maniacal-depressive patients. Not only do they average long, but, with one exception, the average reactions of both the extreme and the less marked maniacal, and of all the depressed with one exception, are above the normal. These data are not novel. They agree with the reaction experiments of Franz.

In view of the unequivocal testimony of the averages, it is somewhat disappointing to note that there is no direct correspondence between the duration of the ocular reactions and the clinical judgment of the severity of the disease. It is hardly an accident that in spite of the high averages in cases of mania the most extreme maniacal excitement had the shortest ocular reaction; while the maniacal group, which averages the longest, is that of the less marked excitement. In view of the complication of the reaction-process and the number of unanalysed factors, we feel that any hypothesis of the effect of the disease on the reaction must be regarded as tentative. But on grounds which will appear most clearly in the discussion of the pursuit-reactions, we believe that the inconsequential reactions of maniacal excitement are due to opposed tendencies in the inter-relation of the superior and the secondary central systematizations.

\section{(3) Ocular Pursuit-Reactions.}

\section{(A) Theory.}

The third series of tests was a reaction experiment of unusual character. The simplest and, in the end, also the most complex ocular reaction with which we are acquainted is the pursuit-movement in reaction to a moving pendulum.

It is the simplest, in the sense that no new object of regard is furnished as stimulus for reaction. There is no change in the object of attention. An object is fixed, and the fixation lapses through the movement of the object fixed. The re-establishment of the lapsed fixation involves a form of ocular reaction such as occurs on an average several times a minute throughout the waking day, either because the object moves or because of involuntary displacement of the eyes by bodily movements. Pursuit-reactions, as we may call them, normally 
involve a reaction-time slightly longer than the simple reactions to peripheral stimuli. At least one factor tending to lengthen the pursuitreaction appears directly in the form of the stimulus. The stimulus to reaction is not given in the release of the pendulum, but only when, after release, the pendulum has moved some appreciable distance. The amount of movement that will constitute a stimulus to pursuit will depend on the training of the subject and the accuracy with which he maintains his fixations.

Paradoxical as it might at first seem, the total pursuit-reaction finally involves more extensive psychomotor: elaboration than any other ocular reaction that we know how to produce. As is now well known (Dodge [7]), the true pursuit eye-movements are totally different in function and character from the rapid reaction-movements of the eyes by which peripheral objects of interest are fixated. The rapid movements are relatively constant in duration, and they constitute moments of practical blindness. The reason for this eye-movement blindness is still under discussion. There is no debate concerning the fact. The pursuitmovements, on the other hand, vary in angle-velocity with the anglevelocity of the moving object. The eyes move fast or slowly as the object moves fast or slorvly. Moreover, the pursuit-movements are pre-eminently moments of relatively clear vision. It is because we wish to see an object clearly that we move the eyes as the object moves and keep its image on retinal areas of relatively clear vision. Furthermore, the psychomotor elaboration of the simple ocular reaction is fixed by the long-established habit of bringing excitations of the peripheral retina to areas of clear vision. The psychomotor elaboration of the pursuit-movements, on the other hand, is in practically each instance of pursuit an unique pyschomotor problem. The reaction to pursuit is fixed and habitual enough, but the velocity of the eye which shall correspond to the velocity of the object at the distance it chances to be can scarcely ever be a motor habit. To be a successful pursuit there must be an adaptation of the general pursuit tendency to the peculiar condition of each separate instance. Especially in the pendulum pursuit-movements are these conditions so various as to present, in each new case, practically unique conditions. Angle-velocity, apparent amplitude, and period of oscillation would all be alike only if pendulums of the same length swing through the same arc at the same distance from the eye of the observer. Yet unique as each case actually is, a normal eye will fall into an adequate pendulum pursuit-movement with surprising quiclsness and accuracy. In every normal individual the very first fixation after 
the initial reaction to a moving pendulum has the characteristic true pursuit-slide, even though it usually corresponds in angle-velocity to the first part of the pendulum swing, and is consequently too slow. Let us emphasize the fact: for normal individuals, however inadequate the first attempt to fix the moving object may be, it always has the characteristics of a true pursuit-movement (see Plate 2, lines $1,10,11$ ).

The return swing of a second pendulum is usually followed with precision, except at or near the middle of the arc of oscillation, when one or two short, sharp, rapid movements break the simple pendulum pursuits. The character of these pendulum pursuits scarcely alters, even after a large number of experiments under the same objective condition. Each new pursuit seems to be solved de novo, and the shortlived motor habits involved in every adequate pursuit seem to be lost when the pursuit is interrupted [8].

This ability to elaborate adequate pursuit-movements, i.e., to adopt an adequate motor response to the peculiar situation presented by the rhythmic movements of an object, varies widely in mental disease. In some respects, the most marked variations are found in the pendulum pursuit-movements in dementia præcox, where a marked hesitation to fall into the swing of the pendulum was found even in the mildest cases. While this peculiarity is apparently not absolutely restricted to dementia precox, it was found in other patients only where the disease-process has produced marked deterioration.

\section{(в) Experimental Conditions.}

The instrumental device for producing the pursuit-reaction and the subsequent pursuit-movements was a number attached to the bob of a second pendulum. The latter hung just in front of the fixed screen with its axis vertically above the middle point between the extreme left and right hand opening. Before the experiment the pendulum was held out of equilibrium in front of the left hand opening by a simple catch attached to a falling screen in the usual place behind the fixed screen. This falling screen was released by the operator, as in the other experiments, and the release of the screen simultaneously started the pendulum and opened the way for the recording beam of light. In every case the patient was previously shown how the pendulum moved and was then requested to watch the number closely, to keep his eyes on it, not to lose it, watch it, \&c. 
(c) Results.

TABLE III.

Ocular Reactions in Pursuit of a Moving Stimulus.

(1) Normal.

$$
\begin{array}{llllll}
1 & \ldots & \text { R. D. } & \ldots & 198 \\
2 & \ldots & \text { A. } & \ldots & \ldots & 233 \\
3 & \ldots & \text { Wh. } & \ldots & 243 \\
4 & \ldots & \text { Wr. } & \ldots & 210
\end{array}
$$$$
\text { Average } \quad \ldots \quad \ldots \quad 221
$$$$
\begin{array}{llllll}
5 & \ldots & \mathbf{H} & \ldots & \ldots & 274
\end{array}
$$$$
\begin{array}{llllll}
6 & \ldots & \text { T. } & \ldots & \ldots & 274 \\
7 & \ldots & \text { T. } & \ldots & \ldots & 284
\end{array}
$$$$
7 \text {.. } \quad \text { Wi. } \quad \ldots .216
$$$$
\begin{array}{llllll}
8 & \ldots & \text { C. } & \ldots & \ldots & 225 \\
\hline & \ldots & \text { L } & \ldots & & \\
\hline & & &
\end{array}
$$$$
\begin{array}{lllll}
9 & \ldots & \text { Ll. ... } & \text {.. } & 265 \\
& & &
\end{array}
$$$$
10 \quad \ldots \quad \text { E. F. } \quad \ldots \quad 285
$$$$
\text { Average } \quad \ldots \quad \ldots 258
$$$$
11 \quad \ldots \quad \text { W. S. } \quad \ldots .235
$$$$
\begin{array}{llllll}
12 & \ldots & \text { J. R. } & \ldots & 223
\end{array}
$$$$
\text { Average } \quad \ldots \quad \ldots \quad 229
$$$$
17 \quad \ldots \quad \text { M. D. }
$$$$
\text { .. } 223
$$

$\begin{array}{llll}\text { Average } & \ldots & \ldots & 239 \\ \text { High } & \ldots & \ldots & 285 \\ \text { Low } & \ldots & \ldots & 198\end{array}$

(4) Dementia Precox.

Marked.

$$
\begin{array}{llllll}
36 & \ldots & \text { A. R. } & \ldots & 305 \\
37 & \ldots & \text { M. } & \text { B. } & \ldots & 195 \\
\multicolumn{5}{c}{\text { Moderate. }}
\end{array}
$$

\begin{tabular}{|c|c|c|c|}
\hline \multicolumn{4}{|c|}{ Slight. } \\
\hline $42 \quad \ldots$ & B. M. & $\ldots$ & 27 \\
\hline $\begin{array}{l}\text { Average } \\
\text { High }\end{array}$ & & & \\
\hline $\begin{array}{l}\text { High } \\
\text { Low }\end{array}$ & & $\cdots$ & \\
\hline
\end{tabular}

39 ... A. McI. ... 207

$\begin{array}{lllll}40 & \ldots & \text { G. L. } & \ldots & 260\end{array}$

$41 \quad \ldots \quad$ M. F. $\quad \ldots .215$
(2) MIANIA.

\section{Marked.}

$13 \quad \ldots \quad$ S. S. $\quad \ldots \quad 190$

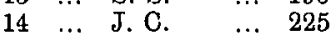

$\begin{array}{lll}14 & \ldots 22\end{array}$

$\begin{array}{lllll}16 & \ldots & \text { M. M. } & \ldots & 222 \\ 18 & \ldots & 343\end{array}$

$\begin{array}{lllll}18 & \ldots & \text { T. S. } & \ldots & 217\end{array}$

19 ... J. G. $\quad \ldots \quad 225$

$20 \quad \ldots \quad$ s. K. $\quad \ldots .314$

Arerage $\quad . . \quad \ldots 248$

Less Marked.

$\begin{array}{lllll}31 & \ldots & \text { I. K. (c) } & \ldots & 260\end{array}$

\begin{tabular}{|c|c|c|c|c|}
\hline 22 & . & G. $\ldots$ & & 210 \\
\hline 29 & $\ldots$ & R. R. (a) & $\ldots$ & \\
\hline 23 & $\ldots$ & P. A. & $\ldots$ & \\
\hline 20 & $\ldots$ & S. K. (c) & $\ldots$ & \\
\hline 24 & $\ldots$ & P. B. & $\ldots$ & \\
\hline 25 & $\ldots$ & P. R. & $\ldots$ & \\
\hline & age & $\cdots$ & $\ldots$ & \\
\hline & & & $\ldots$ & \\
\hline & & & $\cdots$ & \\
\hline & $y$ & & & \\
\hline
\end{tabular}

$21 \quad \ldots \quad$ A. H. $\quad \ldots .217$

$27 \quad \ldots$ M. G. (c. $d) \quad 305$

$33 \quad \ldots \quad$ K. B. $(b) \ldots . \quad 255$

$\begin{array}{llll}\text { Average } & \ldots & \ldots & 259\end{array}$

Hypomania.

(5) Dementia Paralytica. Marked.

$$
\begin{array}{lllll}
43 & \ldots & \text { D. D. } & \ldots & 445 \\
44 & \ldots & \text { W. H. } & \ldots & 240 \\
45 & \ldots & \text { A. B. } & \ldots & 224 \\
47 & \ldots & \text { A. S. } & \ldots & 267 \\
\multicolumn{5}{c}{\text { Less Marked. }}
\end{array}
$$

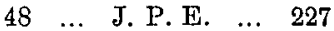

Average $\quad \ldots \quad \ldots \quad 281$

$\begin{array}{llll}\text { High } & \ldots & \ldots & 445 \\ \text { Lowy } & & & \end{array}$

Low Average excluding

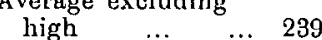

(3) Depression.

Marked.

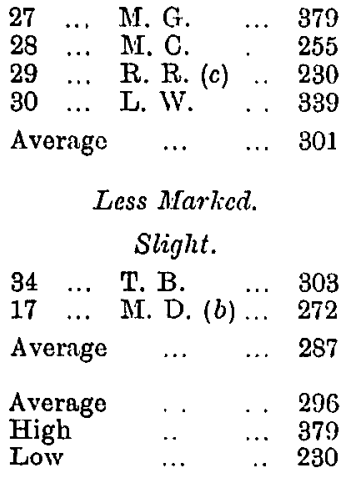

Moderate.

\begin{tabular}{llllll}
51 & $\ldots$ & G. L. & $\ldots$ & 280 \\
52 & $\ldots$ & J. F. & $\ldots$ & 222 \\
53 & $\ldots$ & H. & O. & $\ldots$ & 230 \\
54 & $\ldots$ & M. & B. & $\ldots$ & 221 \\
\multicolumn{2}{l}{ Average } & $\ldots$ & $\ldots$ & 238
\end{tabular}


TABLE IV.

Table of Comparison of Averages.

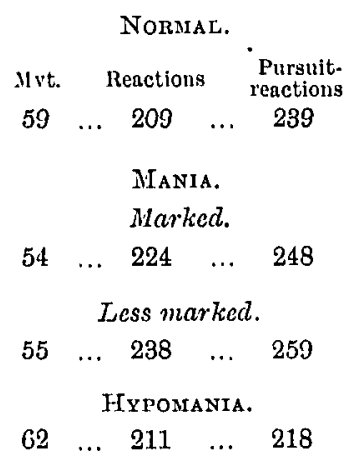

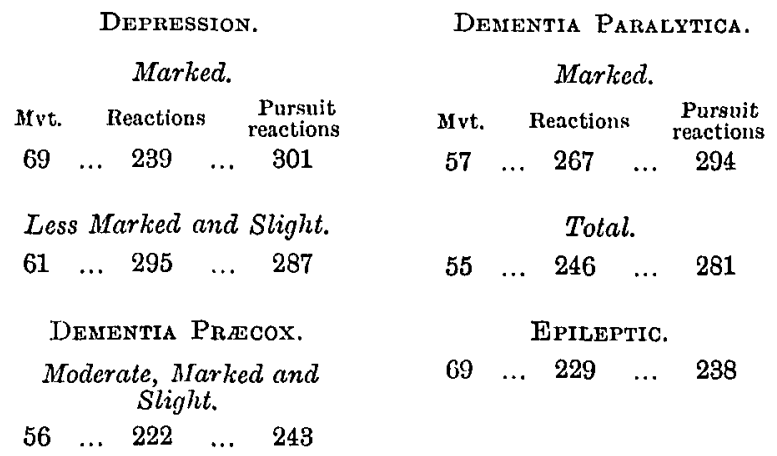

(D) Discussion of Table III.

In all classes except in moderate depression the pursuit-movement reaction averages longer than the simple ocular reaction. The differences between the two, however, are not constant. Even in the group of normal persons the differences are not constant. The variations, however, allow of some degree of classification. It must be remembered that the stimulus to pursuit-movement is not mechanically fixed as was the stimulus to a new peripheral stimulus. The movements of the pendulum operate as a stimulus to pursuit only when the lapsed fixation in some way makes itself felt through the indistinctness of the object. For the trained observer it operates almost immediately. For the less trained it operates only after the pendulum has moved some clearly appreciable distance. The mean difference between pendulum- and pursuit-reactions for normal observers under the conditions of our test was approximately $30 \sigma$. This average difference holds approximately the same for præcox and for the longer reactions of paresis. It does not hold for maniacal-depressives. But the individual variations are so great that the maniacal-depressive differences can scarcely be spoken of as characteristic. It does, however, constitute additional evidence of a high degree of disturbance of those complex superior central processes which are usually grouped under the general name of attention. Further evidence to the same effect comes from a consideration of minimal reactions, which are given in Table V. 
Table V.

Table of Minimal Reactions.

\begin{tabular}{rrrrr}
\multicolumn{5}{c}{ Nondal. } \\
1 & $\ldots$ & 180 & $\ldots$ & 180 \\
2 & $\ldots$ & 180 & $\ldots$ & 200 \\
3 & $\ldots$ & 206 & $\ldots$ & 230 \\
4 & $\ldots$ & 200 & $\ldots$ & 200 \\
5 & $\ldots$ & 166 & $\ldots$ & 260 \\
6 & $\ldots$ & 230 & $\ldots$ & 273 \\
7 & $\ldots$ & 128 & $\ldots$ & 179 \\
8 & $\ldots$ & 243 & $\ldots$ & 179 \\
9 & $\ldots$ & 200 & $\ldots$ & 240 \\
10 & $\ldots$ & 180 & $\ldots$ & 260 \\
11 & $\ldots$ & 140 & $\ldots$ & 200 \\
12 & $\ldots$ & 210 & $\ldots$ & 210 \\
17 & $\ldots$ & 220 & $\ldots$ & 190 \\
Avorago & 191 & $\ldots$ & 216 \\
\end{tabular}

\begin{tabular}{ccccc}
\multicolumn{5}{c}{ ManIA. } \\
13 & $\ldots$ & 180 & $\ldots$ & 180 \\
14 & $\ldots$ & 180 & $\ldots$ & 180 \\
16 & $\ldots$ & 186 & $\ldots$ & 257 \\
17 & $\ldots$ & 205 & & \\
18 & $\ldots$ & 210 & $\ldots$ & 200 \\
19 & $\ldots$ & 160 & $\ldots$ & 210 \\
20 & $\ldots$ & 182 & $\ldots$ & 257 \\
& & 186 & $\ldots$ & 214 \\
31 & $\ldots$ & 230 & $\ldots$ & 240 \\
21 & $\ldots$ & 190 & $\ldots$ & 210 \\
27 & $\ldots$ & 230 & $\ldots$ & 280 \\
33 & $\ldots$ & 190 & $\ldots$ & 190 \\
& & 210 & $\ldots$ & 230 \\
& & & & \\
22 & $\ldots$ & 210 & $\ldots$ & 200 \\
23 & $\ldots$ & 210 & $\ldots$ & 200 \\
20 & $\ldots$ & 190 & $\ldots$ & 200 \\
24 & $\ldots$ & 150 & $\ldots$ & 140 \\
25 & $\ldots$ & 210 & $\ldots$ & 220 \\
& & 194 & $\ldots$ & 192 \\
Avernge & 195 & $\ldots$ & 211
\end{tabular}

\begin{tabular}{lllll}
\multicolumn{5}{c}{ Depression. } \\
26 & $\ldots$ & 200 & & \\
27 & $\ldots$ & 279 & $\ldots$ & 244 \\
28 & $\ldots$ & & $\ldots$ & 228 \\
29 & $\ldots$ & 170 & $\ldots$ & 210 \\
& & 216 & $\ldots$ & 227 \\
& & & & \\
34 & $\ldots$ & 240 & $\ldots$ & 800 \\
$17(b) \ldots$ & 186 & $\ldots$ & 248 \\
& & 213 & $\ldots$ & 274 \\
Avcrage & 215 & $\ldots$ & 246
\end{tabular}

Dementra Precox.

Dementia Paralytica.

Epileptic.

$\begin{array}{lllllllllllllll}36 & \ldots & 200 & \ldots & 260 & 43 & \ldots & 350 & \ldots & 290 & 51 & \ldots & 270 & \ldots & 250 \\ 37 & \ldots & 180 & \ldots & 190 & 44 & \ldots & 220 & \ldots & 200 & 52 & \ldots & 200 & \ldots & 200 \\ 38 & \ldots & 248 & & & 45 & \ldots & 210 & \ldots & 210 & 53 & \ldots & 190 & \ldots & 210 \\ & & & & & 47 & \ldots & 230 & \ldots & 240 & 54 & \ldots & 170 & \ldots & 200 \\ 39 & \ldots & 260 & \ldots & 167 & & & & & & & \text { Avernge } & 207 & \ldots & 215 \\ 40 & \ldots & & \ldots & 240 & 48 & \ldots & 170 & \ldots & 210 & & & & & \\ 41 & \ldots & 200 & \ldots & 180 & 49 & \ldots & 180 & & & & & & & \\ 42 & \ldots & 150 & \ldots & 230 & 50 & \ldots & 180 & & & & & & & \end{array}$

Discussion of the Table of Minimal Reactions (Table V.).

In some respects the minimal reactions for any well-established type of reaction is more instructive than the average reaction. The minimal reaction shows the reflex systematization in its highest state of efficiency. The mean reaction indicates the average state of efficiency. The two differ from one another by the mean value of all those disturbing elements that may complicate the reaction-process. It seems to the writers a very significant fact that the average minimal reaction of extreme maniacal excitement is below the average minimum of normal subjects. It is not much below the normal, but it is not above it as the total average is. Moreover, the mean variation of the minimal reactions 
is approximately the same as the mean variations of the averages. This consistent uniformity is not accidental. In connexion with the adequate pursuit-reactions it seems to the writers to constitute unequivocal evidence that the oculo-motor: systematization is not seriously disordered in acute mania. The large mean value of disturbing elements constitutes the final point that we have to offer in the cumulative experimental evidence that extreme mania involves a marked disturbance of the controls normally exercised by the superior central systematizations.

This seems to the writers to coincide closely with the general clinical picture of marked mania. The motor organization even for complex acts is not lost. The incapacity for regular employment is flagrantly due to gross disturbances of the normal controls within the higher systematizations. Tentatively, at least, we may picture this in terms of an inhibition of the free interaction of the various factors in the normal complex superior organization.

Provided there is some intrinsic retardation of the intermediate systematizations, like the simple oculo-motor reflexes, we should expect to find the total evidences of maniacal excitement less marked. In such cases we should expect the minimal reactions to be long as well as the average reactions. This is actually the case in less marked mania. It looks as though the inhibitory processes involved in the disease were affecting lower centres. The climax of this downward progression seems to be reached when, in extreme depression, the resistance to neural interaction involves the simplest reflexes.

In contrast to the differential increase of resistance to neural activity as found in the maniacal-depressives, our experimental data from the demented point to a general disorganization of the central systematizations.

In dementia paralytica the entire nervous system is involved in this disorganization, as is shown by the marked retardation, and the inefficiency of the simplest, as well as of the higher reflexes (patellar, pupillary, and cerebellar).

In precox the disorganizations seem to be primarily limited to the superior systematizations. This is shown negatively by the rapid eyemovements, normal oculo-motor reactions, and positively by the difficulty of adopting adequate reactions to new conditions of the environment, as in the pursuit-movements. This latter peculiarity of præcox patients has a practical as well as a theoretical interest.

Practically, it is an important differentiating symptom between moderate maniacal excitement and developing precox, i.e., between two 
psychoses whose differential diagnosis is of the utmost importince and often of the utmost difficulty. Unfortunately the faultiness of t: e pursuit is not easily detected by direct observation. Photographic registration, although remarkably simple as a scientific technique, is rather too expensive in time and apparatus for regular professional use. If the matter prove worth while, a simplified recording apparatus is probably the only safe and practicable solution. It would seem strange,

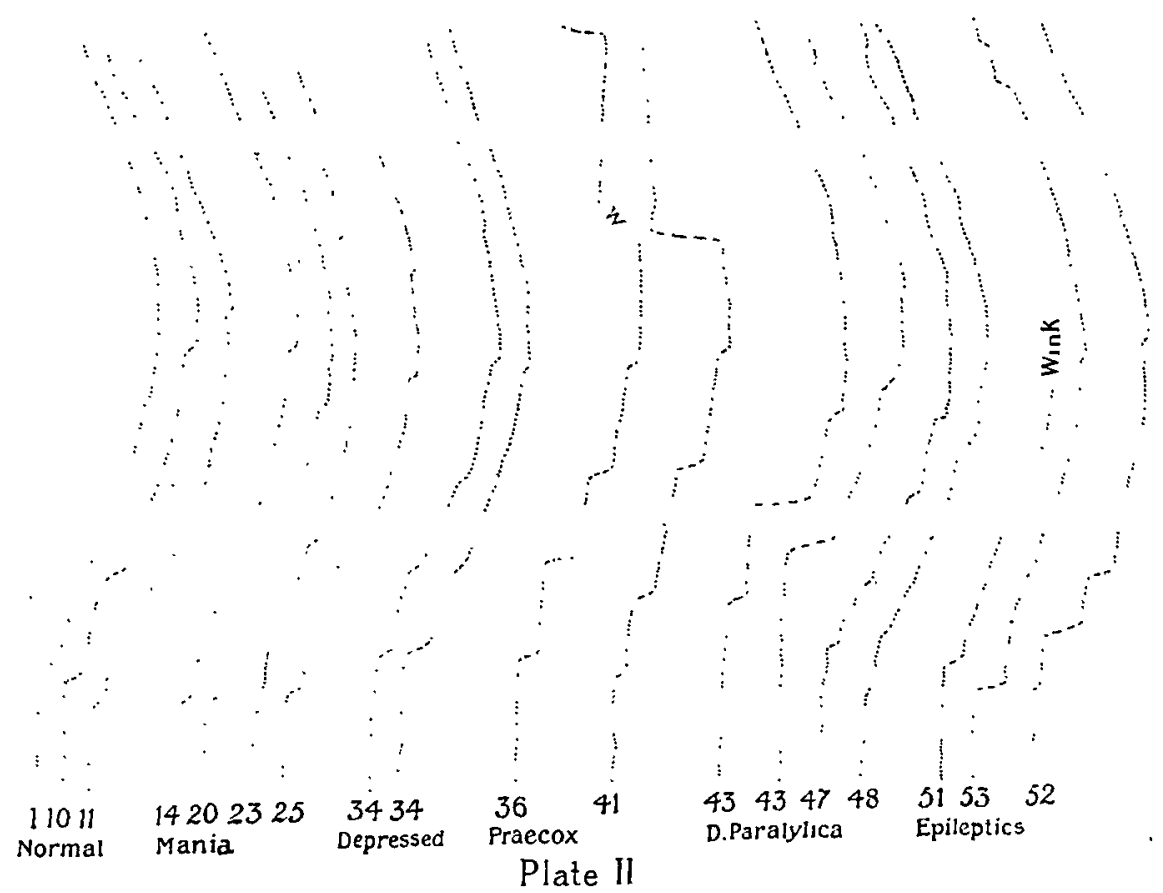

Plate II. is reproduced from drawings of typical pursuit-reaction records. It shows most of the typical variations of the visual pursuits so far as they were not complicated by gross head. movements. The lines accurately reproduce only the general configuration of the pursuit.

Each line, reading from the bottom up, represents one complete pursuit-swing corresponding to a double oscillation of the second pendulum. Since the release of the pendulum and the beginning of the record are synchronous, the straight line at the beginning of each record gives the reaction-time. The reaction begins with a sharp horizontal movement to the right. This is followed by the slow pursuit swing, which is more or less adequate according to the nature of the disease. The præcox pursuits, Nos. 36 and 41, are typical. In mild cases tho hesitation to adopt the pursuit-swing is less pronounced, but it is regularly shown by straight lines somewhere in the pursuit. The maniacal pursuit shows a tendency to get ahead of the pendulum (see upper part of lines 14, 23 and 25). This tendency sometimes appears in the first positive acceloration of the pendulum in maniacal cases. It is not entirely absent from normal pursuits or from moderate depression. In the latter cases, however, it is very rare. Other modifications of the pursuit are suggestive, but at present they permit no generalized statement.

The double breaks in each record are occasioned by the swinging of the pendulum through the recording beam of light. 
however, if similar phenomena cannot be found in other forms of reaction which are more accessible to direct observation.

The theoretical bearing of the inadequate ocular pursuit-movements of præcox we have already mentioned. It was not overlooked by us that the simplest explanation of the phenomenon would be to coördinate it with those processes which are ordinarily grouped under the head of faulty attention. This explanation seems to us untenable on the following grounds:-

(1) Equally grave defects of "attention" exist in maniacal excitement without parallel difficulty of pursuit.

(2) The reaction-times do not indicate gross defects of "attention" in moderate præcox.

(3) Reasonable "attention" and effort at pursuit are both clearly indicated in the number and character of the short corrective movements.

Finally, the phenomenon seems to connect itself naturally with certain characteristic clinical observations of præcox as one manifestation of the patient's inability to adapt himself to new and unusual requirements of his environment. Put technically, it is the patient's inability to adopt adequate short-lived habits in response to a new recurrent situation. There is some clinical evidence that this motor phenomenon rests on a basis of faulty elaboration of the perceptual data. Our experiments indicate that the intellectual defect is a matter of inadequate appreciation rather than a matter of attention.

The writers take this opportunity to express to Dr. H. S. Noble, Superintendent of the Connecticut Hospital for the Insane, their cordial appreciation of his sympathetic interest and encouragement which made this series of experiments possible.

The Appendix contains a brief account of each case by Dr. Diefendorf, together with all the unambiguous comparative data from the photographic records.

\section{APPENDIX.}

\section{NORMALS.}

Mvt. Simp. R. Pend. R.

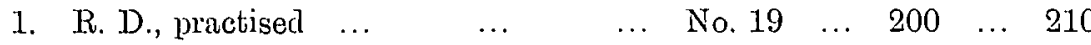

Av. $59 \quad 220 \quad \ldots, 190$

$\begin{array}{lll}180 & \ldots & 180\end{array}$

- 210

198 
Mvt. Simp. R. Pend. R.

2. A., student

$$
\begin{array}{rrrrrr}
\text { N. No. } 13 & \ldots & 180 & \ldots & 200 \\
& \text { Av. } 59 & \ldots & 220 & \ldots & 240 \\
& & & & & 260 \\
& & & & & \\
& & & & & 233
\end{array}
$$

3. Wh., student

$\begin{array}{rrrrrr}\text { N. No. } 7 & \ldots & 210 & \ldots & 230 \\ & \text { Av. } 61 & & 230 & \ldots & 256 \\ & & 206 & & \\ & & & & 243\end{array}$

4. Wr., student

$$
\begin{aligned}
& \begin{array}{lllllll}
\ldots & \text { No. } & 8 & \ldots & 230 & \ldots & 220
\end{array} \\
& \text { Av. } 60 \quad 200 \quad \ldots \quad 200 \\
& 210 \quad \ldots \quad 210 \\
& 200 \quad \frac{}{210}
\end{aligned}
$$

5 to 10.-Female Nurses.

5. H., aged 64

$$
\begin{array}{cccccc}
\ldots & \text { Series } & \ldots & 230 & \ldots & 292 \\
& \text { I. No } & & 166 & \ldots & 273 \\
& \text { Mvts. } & & 204 & \ldots & 260 \\
& & & 166 & \ldots & 273 \\
& & & 192 & & 274 \\
& & & & & \\
& & & \\
& \text { Series } & \ldots & 260 & \ldots & 293 \\
& \text { I. No } & & 230 & \ldots & 273 \\
& \text { Mvts. } & & 256 & \ldots & 287 \\
& & & & & \\
& & & & & \\
& & & & &
\end{array}
$$

6. T., aged 65

7. Wi., aged 67

$$
\begin{aligned}
& \begin{array}{llllll}
\ldots & \text { Series } & \ldots & 153 & \ldots & 199
\end{array} \\
& \begin{array}{llll}
\text { I. No } & 128 & \ldots & 205
\end{array} \\
& \begin{array}{llll}
\text { Mvts. } & 133 & \ldots & 282
\end{array} \\
& \begin{array}{lll}
148 & \ldots & 179
\end{array} \\
& \overline{140} \quad \overline{216}
\end{aligned}
$$

8. C., aged 69

$$
\begin{array}{rlllll}
\text { Series. } & \ldots & 251 & \ldots & 230 \\
\text { I. No } & & 243 & \ldots & 179 \\
\text { Mvts. } & & & & & 235 \\
& & & & & \\
& & & & & 256
\end{array}
$$


Mvt. Simp. R. Pend. R.

9. Li., aged 45

\begin{tabular}{|c|c|c|c|}
\hline No. 26 & 260 & $\ldots$ & 250 \\
\hline \multirow{4}{*}{ Av. 60} & 210 & $\ldots$ & 320 \\
\hline & 200 & $\ldots$ & 250 \\
\hline & & & 240 \\
\hline & 223 & & \\
\hline
\end{tabular}

10. E. F., aged 46

$\begin{array}{rrrrrr}\text { No. } 22 & \ldots & 180 & \ldots & 260 \\ \text { Av. } 54 & & 216 & \ldots & 310 \\ & & & & & \\ & & & 195 & & 285\end{array}$

Male Nurses.

11. W. S., aged 38

\begin{tabular}{|c|c|c|c|}
\hline No. 24 & 260 & $\ldots$ & 270 \\
\hline \multirow{4}{*}{ Av. 62} & 140 & $\ldots$ & 220 \\
\hline & 210 & $\ldots$ & 200 \\
\hline & 180 & $\ldots$ & 250 \\
\hline & 198 & & \\
\hline
\end{tabular}

12. J. R., aged 39

$\begin{array}{lrrrrr}\text {.. No. } 7 & \ldots & 220 & \ldots & 240 \\ & \text { Av. } 60 & & 260 & \ldots & 210 \\ & & & 210 & \ldots & 220 \\ & & & 210 & & \\ & & & & 223\end{array}$

Recovered Patient.

See 17, M. D. (c) for full record ... .. Av. $60 \quad \ldots \quad 222$ 223

\section{MANIACAL-DEPRESSIVE INSANITY.}

Maniacal Phase, Marked.

13. S. S., F., aged 49. Second attack of two months duration. A. T.2-Extreme pressure, with impulsiveness. Marked spontaneity, flight of ideas, distracti$\begin{array}{rrrrr}\text { No. } 8 & \ldots & 180 & \ldots & 200 \\ \text { Av. } 59 & & 230 & \ldots & 180 \\ & & & & \\ & & & & \\ & & & & \end{array}$ bility, and irritability. I. A. ${ }^{8}$ - Held with great difficulty. Many readjustments necessary. Shouted. Commented. Added figures.

1 The letters $F$, and M. after the pationt's iuitials refer to the patient's sex.

: A. 'T. gives the patient's condition at the time of examination.

"I. A. gives the patient's behaviour in the apparatus. 
14. J. C., M., aged 51. Numerous attacks of Mvt. Simp. R. Poud. R. maniacal phase. Present attack of two months duration. A. T.-Marked pressure. Spontaneity. Flight of ideas. Elation. Distractibility. Marked impulsiveness and destructiveness. Person smeared and naked on ward. I. A.-Surprisingly tractable and helpful. Shouted responses.

(b) Second plate several days later. Same conditions.

(a)

\begin{tabular}{|c|c|c|c|}
\hline No. 16 & 180 & $\ldots$ & 215 \\
\hline Av. 45 & 240 & $\ldots$ & 240 \\
\hline & 210 & & \\
\hline & & & 25 \\
\hline & (b) & & \\
\hline No. 8 & 200 & $\ldots$ & 180 \\
\hline Av. 43 & 220 & $\ldots$ & 240 \\
\hline & 230 & $\ldots$ & 240 \\
\hline & $\overline{017}$ & & \\
\hline & 217 & & \\
\hline
\end{tabular}

No. 5

Av. 60 pressure Marked productivity and flight of ideas, distractibility, emotional irritability and elation. I. A.-Tractable, loquacious, distractible. Sluggish. Eyelids sagged. No legible reactions.

16. M. M., F., aged 38. Second attack of two months duration. First of five months duration. Lucid interval of seventeen months. A. T.-Marked excitement. Extreme pressure. Flight of ideas. Trritable. Violent. Destructive. Untidy. Partial orientation. I. A.Remarkable self-control. Obvious suppressed excitement. Voice loud. Many comments.

17. M. D., F., aged 26. Five years duration. For the last three yenrs regular alternation from depressive to maniacal phase without lucid intervals. A. T.Marked pressure. Elation. Distractibility. Flight of ideas. Noisy. Irrit-

$\begin{array}{ccccc}\text { Series } & \ldots & 186 & \ldots & (695) \\ \text { I. No } & & 264 & \ldots & 335 \\ \text { Mvts. } & & - & & 257 \\ & & 225 & & 437 \\ & & & & \\ & & & & 343\end{array}$
able moods. Tore clothing. No deterioration. I. A.-Tractable. Complained that pendulum was blurred.

$\begin{array}{ccc} & & (a) \\ \text { Series } & \ldots & 290 \\ \text { I. No } & & 254 \\ \text { Mvts. } & & 205 \\ & & \\ & & 250\end{array}$


(b) Same at second experiment. Just passed to depressive state. Slight retardation without despondency. Exaggerated feeling of incapacity.

(c) Same five months later. Normal.

18. T. S., M., agsed 67. Maniacal phase of three months duration immediately preceded by depressive phase of fourteen months duration. A. T.-Considerable pressure of activity. Busyness. Constant speech. Flight of ideas. Increased irritability, with elation. Distractibility. I. A.-Talked constantly. Responded correctly and rapidly.

19. J. G., F., ageil 52. Recurrent attacks for many year's, both maniacal and depressive. A. T.-Maniucal phase of two months duration. Considerable pressure. Great productivity. Distractibility. Increased irritability predominating elation. I. A.-Loud responses. Movements seemed deliberate. Kept in position with difficulty. At times refuses to open eyes.

(b) Same. Series of ten reactions.

20. S. K., M., aged 40. Eight years duration. For last three passed immediately from one maniacal state to another, average six months duration. No detorioration. A. T.-Marked excitement. Pressure of activity. Flight of ideas and distructibility. Elation and impulsive outbreaks. Consciousness clear. I. A.-(a) Violent laughter. Intolerant of assistance.
Mvt.

Simp. R. Pend. R.

(b)

$\begin{array}{lll}186 & \ldots & 309\end{array}$

$\begin{array}{lll}222 & \ldots & 263\end{array}$

$-\quad 273$

$204 \quad 248$

273

268

$\begin{array}{llclc} & & (c) & & 272 \\ \text { No. 19 } & \ldots & 225 & \ldots & (300) \\ \text { Av. } 60 & & 220 & \ldots & 210 \\ & & 220 & \ldots & 270 \\ & & 222 & & \overline{190} \\ & & & & 223 \\ \text { No. 11 } & \ldots & 270 & \ldots & 250 \\ \text { Av. 51 } & & 270 & \ldots & 200 \\ & & 210 & \ldots & 200 \\ & & & & \\ & & 250 & & 217\end{array}$

$\begin{array}{lllll}\text { No. } 8 & \ldots & 190 & \ldots & 210 \\ \text { Av. } 54 & & 160 & \ldots & 240 \\ & & 200 & & \\ \text { No. } 13 & \ldots & 290 & & 225 \\ \text { Av. } 56 & & & \\ & & & & \\ & & & \end{array}$

(b)

No. 10

Av. 204

M. V. 11

(a)

Illegible. Too much head-movement.

(b)

$\begin{array}{lllll}\text { Series } & \ldots & 275 & \ldots & 342\end{array}$

I. No $\quad 261 \quad \ldots \quad 347$

$\begin{array}{llll}\text { Mvts. } & 199 & \ldots & 308\end{array}$

$\begin{array}{lll}182 & \ldots & 257\end{array}$

$\overline{229} \quad \overline{314}$ 
(b) Less intractable.

Mvt. Simp. R. Pend. R.

(c) Same five months later. Somewhat improved. Hypomania. Tractable. Responds rapidly. Attends well.

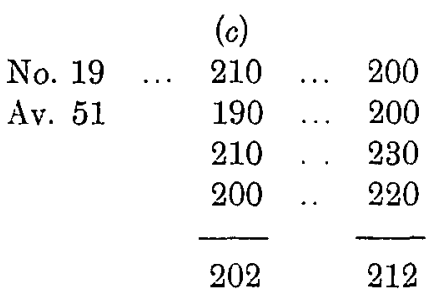

Maniacal Phase, Less Marked.

31. L. K., F., aged 63. Maniacal excitement after moderate depression. See description under depressive phase, less marked, $31(b)$ and $(c)$. No. 25 ... No. 4 ... Av. 60 260 260

21. A. H., M., aged 73. Third attack of six months duration. A. T.-Irritability, with predominating elation. Pressure of activity. Flight of ideas. Distractibility. I. A.-Very tractable. Responses correct and rapid. No evident disturbance of attention.

27. M. G., F., aged 60. Moderate mania after extreme depression. Sce description under depressive phase, marked, 27 (c) and $(d)$.

33. K. B., F., aged 44. Moderate mania after moderate depression. See description under depressive phase, less marked, $33(b)$.

$$
\begin{array}{llclc}
\text { No. } 5 & \ldots & (265) & \ldots & 220 \\
\text { Av. } 56 & & 215 & \ldots & 210 \\
& & 240 & \ldots & 220 \\
& & 190 & \ldots & \text { W. } \\
& & & & \\
& & & & \\
& & & &
\end{array}
$$

No. 22 ... No. 3 ... No. 6 Av. $47 \quad 257 \quad 305$ $\begin{array}{lcccc}\text { No. } 14 & \ldots & \text { No. } 4 & \ldots & \text { No. } 4 \\ \text { Av. } 59 & & 219 & & 255\end{array}$

\section{HrPomania.}

22. G., M., aged 18. First attack eighteen months duration. A. T.-Slight pressure. Mischievous and boisterous. Considerable spontaneity of speech with rambling thought. Distractibility. Irritability. I. A.-Excellent behaviour. Held himself.

$\begin{array}{rrrrr}\text { Av. } 50 & \ldots & 220 & \ldots & 220 \\ & & 230 & \ldots & 210 \\ & 260 & \ldots & 220 \\ & 210 & \ldots & 200 \\ & & & 210 \\ & & & 200 \\ & & & & \\ & & & & \end{array}$

29. R. R., F., aged 14. Hypomania pre- Av. 65 Av. 220 ceding marked depression. For description see under depressive phase, marked, $29(a)$. 
Nivt. Simp. R. Pend. $R$.

23. P. A., F., aged 59. Many attacks, mostly maniacal, for thirty-three years. A. T.-Just emerging from maniacal phase of two weeks duration. Slight irritability, distractibility and loquacity. I. A.-Quite tractable. Commented on apparatus and added figures.

20. S. K., M., aged 40. Hypomania following pronounced maniacal state. For description sce under maniacal phase, marked, $20(c)$.

24. P. B., M., aged 27. Second attack of two weeks duration. A. T.-Moderate busyness. Slight elation. Flight of iders, spontaneous speech. I. A.-Excellent behaviour. Good interest.

$\begin{array}{lllll}\text { No. } 19 & \ldots & 230 & \ldots & 260\end{array}$

Av. $76 \quad 240 \quad \ldots \quad 250$

$220 \quad$.. 200

$210 \quad \ldots \quad 250$

$\overline{225} \quad \overline{240}$

No. $19 \quad \ldots \quad 202 \quad \ldots \quad 212$

Av. 51

$\begin{array}{rrrrrr}\text { No. } 6 & \ldots & 150 & \ldots & 140 \\ \text { Av. } 61 & & 190 & \ldots & 170 \\ & & & \\ & & & & & 155\end{array}$

No. $10 \quad \ldots \quad(390) \quad \ldots \quad 285$

.Av. $70 \quad 240 \quad \ldots \quad 315$

$240 \quad \ldots \quad 220$

$210 \quad \overline{273}$

230

\section{ManiaCat-Depressive Insanity.}

\section{Depressive Phase, Marked..}

26.-H. N., F., aged 34. Second attack. Two months duration. Three days before test patient suddenly changed overnight from active maniacal state to stuporous state. A. T.-Profound retardation of thought, attention and action. Complete disorientation. Fogged consciousness. Feeling of inadequacy. I. A.Somewhat resistant. Slow, partially inaudible responses. Better at end.

(b) Same next day. Condition unchanged. Responded only after urging.

(c) Same next day. Slight improvement. Series of eight reactions as test. (a)

No. $9 \begin{array}{lllll} & \ldots & 235 & \ldots & \text { Pursuit }\end{array}$

Av. $53 \quad 275$ on second

- 250 swing.

(b)

No. $\begin{array}{lllll}7 & \ldots & 240 & \ldots & \mathrm{No}\end{array}$

Av. 55200 pursuit.

200

250

222

(c)

No. 11 ... No. 8 ... No

Av. 56 Av. 206 pursuit.

M. V. 20 
27. M. G., F., aged 60 . For years alterMvt. Simp. R. Pend. R. nating attacks of maniacal-depressive insanity without lucid intervals. No evident deterioration. A. T.-Extreme despondency. Marked retardation. No voluntary speech or activity. Almost inaudible replies. Marked self-accusation. Without illusions or hallucinations. Perfect orientation. I. A.-Slow faint responses.

(b) Same several days later. Retardation less marked. Occasional remark. Entrance and exit from room now without prodding. Reactions apparently good.

(c) Same five months later. Moderate mania with slight pressure. Moderate distractibility and flight of ideas. I. A. -Tractable. Poor attention.

(d) Same next day. Still more distractible owing to presence of visitors.

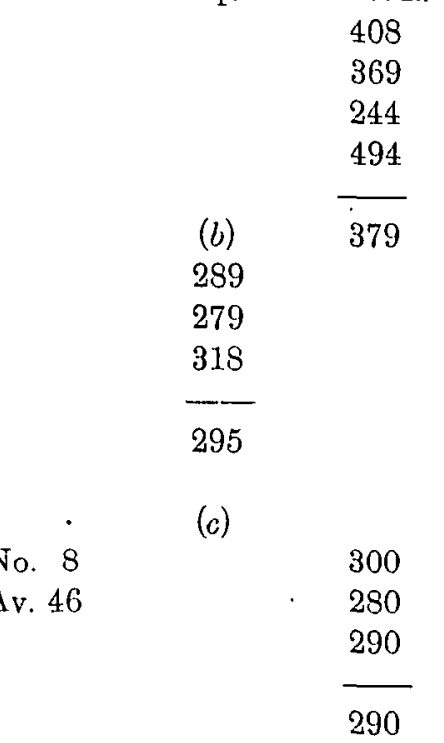

(d)

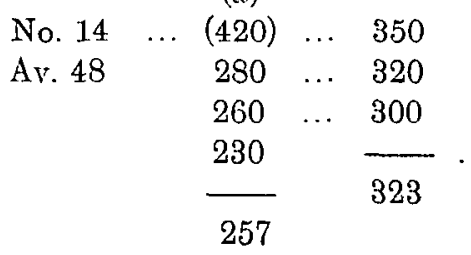

28. M.C., F., aged 45. Third attack of mani228 acal-depressive insanity, depressive phase of nine months duration. No hallucinations, illusions or deterioration. A. T.Marked retardation evident in attention, train of thought and volition. No voluntary speech. Meagre and slow responses. Various delusions of self-accusation. Emotionally depressed and apprehensive.

29. R. R., F., aged 14 . Numerous attacks of maniacal phase and one of depressive within last twelve months. A. T.- $(a)$ Hypomania. Moderate elation, producAv. 65 tivity, flight of ideas and distractibility. Busyness. I. A.-Tractable. Excellent reactions. 
Mvt. Simp. R. Pend. R.

(c) Same six days later. Marked depressive

(b)

stage. Profound despondency. Bxtreme rotardation. No voluntary speech. Sluggish movement. I. A.-Timid. Shrinking from nose-piece. Responses slow, almost inqudible, and only after urging.

30. L. W., E., aged 57. For fifteen years recurrent attacks of maniacal-depressive insanity without lucid intervals. A. T. -Depressive phase of two years cluration. Pronounced retardation of thought,

$\begin{array}{lllll}\text { No. } 26 & \ldots & 230 & \ldots & 240 \\ \text { Av. } 70 & & 170 & \ldots & 240 \\ & & 170 & \ldots & 210 \\ & & 180 & \ldots & 200 \\ & & & \\ & & & & 222\end{array}$

(c)

No. $23 \quad \ldots \quad 170 \quad \ldots \quad 260$

Av. $77 \quad 180 \quad \ldots \quad 230$

$\begin{array}{lll}170 & \ldots & 210\end{array}$

$-220$

$173 \quad \overline{230}$ attention and volition. Very little spontaneous speech or activity. Deep emotional depression, without delusions. Good orientation. Some deterioration in memory and judgment. General indifference.

\section{Depressive Phase, Less Marked.}

31. L. K., F., aged 63. For many years alternating attacks of maniacal and depressive phases without intermissions. A. T.- Emerging from depressive attack of several months duration. Considerable rotardation of thought, volition, and attention. Little voluntary speech. Low tones and slow responses were explained by patient as results of "difficulty of thought." Sad and wished to die. No hallucinations or delusions. Good orientation. Clear consciousness. I. A.Tractable.

(b) Same five months later. Maniacal excitemont. Busynoss. Volubility. Pronounced elation. Distractibility. I. A.Tractable. Good attention.

J3hIN.-YOL. XxxI.

\begin{tabular}{|c|c|c|c|c|}
\hline Series & $\ldots$ & $\begin{array}{l}\text { (a) } \\
324\end{array}$ & ..: & 302 \\
\hline I. No & & - & & - \\
\hline Mvts. & & 324 & & 302 \\
\hline
\end{tabular}


(c) Same several days later. Still more maniacal. Great. pressure and productivity. Great distractibility. Difficulty in reading figures. Many mistakes.

Mvt. Simp. R. Pond. R.

\begin{tabular}{|c|c|c|c|c|}
\hline & & $(c)$ & & \\
\hline No. 12 & $\ldots$ & 280 & & \\
\hline Av. 60 & & 290 & & \\
\hline & & 240 & & \\
\hline & & 230 & & \\
\hline & & $\begin{array}{l}260 \\
(a)\end{array}$ & & \\
\hline & & 398 & ... & None \\
\hline & & 360 & & taken. \\
\hline & & 379 & & $\cdot$ \\
\hline & & (b) & & \\
\hline No. 7 & $\ldots$ & 239 & $\ldots$ & Not \\
\hline Av. 69 & & 155 & & clear. \\
\hline & & 253 & & \\
\hline & & 216 & & \\
\hline & & (c) & & \\
\hline No. 11 & $\cdots$ & Refus & & \\
\hline Av. 74 & & to rea & & \\
\hline
\end{tabular}

32. P. F., M., aged 28. For four years numerous attacks of maniacal-depressive insanity. At first alternate depression and elation, of several months duration, with brief lucid intervals. During past year attacks were shorter, more severe and without lucid intervals. A. T.Marked despondency with retardation. Dejected and lachrymose. Moved from seat in ward only occasionally, after insistent prodding. Mengre replies. Complained of numbness, \&c. No hallucinations or delusions. Good orientation. No deterioration.

(b) Same several days later. Mild maniacal excitement of two days duration. Mild pressure of activity, talkativeness and flight of ideas, and distractibility. Elated. Talks of future work. Disoriented as to time. Same several days later. Another dopressive phase. Refused to enter apparatus.

(c) Sime five montlis later. Profound retardation. Slight elation and occasional smiles. I. A.-Tractable. Good attention. Retardation too pronounced to read figures.

33. K. B., F., aged 44. Two months duration. A. T.-Pronounced retardation of thought, attention, and volition. Selfaccusatory delusions. Considerable apprehensiveness. I. A.-Tractable. Poor attention. Needed constant prodding. "Felt sleepy."

(b) Same two days later. Moderate maniacal phase. Better attention. Responses more audible and rapid.

(a)

No. 5 ... None. ... None.

Av. 72

(b)

$\begin{array}{lllll}\text { No. } 14 & \ldots & 225 & \ldots & 240 \\ \text { Av. } 59 & & 250 & \ldots & 190 \\ & & 190 & \ldots & 290 \\ & & 210 & \ldots & 300 \\ & & & \\ & & & \\ & & & & \end{array}$ 


\section{Depressive Phase, Slight.}

Mvt. Simp. R. Pend. R.

34. T. B., F., aged 29. In third attack of No. $13 \quad \ldots \quad 250 \quad \ldots \quad 300$ maniacal-depressivo insanity. First at 21 was depressive. Second at 28 was maniacal. Present attack of six months duration is mildly depressive. No deAv. $51 \quad 240 \quad \ldots \quad 310$ $390 \quad \ldots \quad 300$ terioration. A. T.-Perfect orientation. Retardation evident in train of thought and general lack of activity. Little voluntary speech unless questioned. Speech slow and low. Profoundly dejected and somowhat lachrymose. Some self-accusation. Otherwise no Clelusions.

17. M. D. For full description sec under $204 \quad \ldots \quad 272$ maniacal phase, marked, 17 (b).

\section{Dimmenta PRadoc.}

\section{Hebej]luenic Marked Dementia.}

36. A. R., agod 36. Thirteen year's duriltion. A. T.-Extreme apathy. Inciolence. Paralysis of thought. Silly laughter. Blunted attention. Faulty judgment. I. A.-Poor attention. Eyes $\begin{array}{lllll}\text { No. } 10 & \ldots & 280 & \ldots & 260 \\ \text { Av. } 62 & & 240 & \ldots & 350 \\ & & 200 & & \\ & & & 305\end{array}$ apparently wandered everywhere. In only one of the four reactions were the figuros rend.

37. M. B., F., aged 32 . Seven years duration. A. T.-Desultoriness. Paralysis of thought. Residuals of former erotic dolusions. Occasional hallucinations of hearing. Pronounced defects of memory. I. A. - Apprehensive. Marked headmovomonts. Faulty attention. Figures were apparently road ripidly.

38. R. B., F., anged 26. Six years duration. Marked impaiment of memory and intellect. Marked emotional deterioration. Extreme paralysis of thought. $\begin{array}{llllll}\text { No. } 12 & \ldots & 190 & \ldots & 200 \\ \text { Av. } 52 & & 180 & \ldots & 190 \\ & & & & \\ & & & & & 195\end{array}$ Complete disorientation. Inability to circ for herself. 1. A.-Attention poor. Jerky head-movements. Shut her eyes and looked languidly about. Speech reactions slow or wanting. Records largely illegible owing to head-movements.

\begin{tabular}{lll} 
Selies & $\ldots$ & 268 \\
I. No & & 248 \\
Mvts. & & \\
\cline { 3 - 3 } & & 258
\end{tabular}




\section{Moderate Dementia.}

39. A. McI., F., aged 19. Twenty-one months duration. A. T.-Moderate dementia. Residuals of former grandiose delusions. Moderate defects of memory, paralysis of thought and will. Emotional deterioration. Oriented and without hallucinations. I. A.-Adapted herself readily to the apparatus and seemed to respond easily. Slight apparent retardation.

40. G. L., M., aged 30. Several months duration. From onset moderate despondency with delusions of self-accusation, reference and persecution. Occasional hallucinations of hearing. I. A.Excellent behaviour. Good interest and attention.

41. M. F., M., aged 31. One year's duration. A. T.-Constant aural hallucinations. Consciousness clear. Orientation perfect. Slight defects of memory. Some paralysis of thought. Persecutory and somatic delusions. Diminished emotional and volitional activity.
Mrts

Simp. R. Poud. R.

\begin{tabular}{ccc}
$(415)$ & $\ldots$ & 246 \\
292 & $\ldots$ & 167 \\
260 & & - \\
\hline 276 & & 207
\end{tabular}

$$
\begin{aligned}
& \begin{array}{lllll}
\text { No. } 13 & \ldots & (420) & \ldots & 290
\end{array} \\
& \text { Av. } 60 \quad 260 \\
& 240 \\
& 250 \\
& 260
\end{aligned}
$$

$\begin{array}{lllll}\text { No. } 13 & \ldots & 210 & \ldots & 250 \\ \text { Av. } 50 & & 200 & \ldots & 210 \\ & & 250 & \ldots & 180 \\ & & & 220 \\ & & & & \\ & & & & 215\end{array}$

Slight Dementia.

42. B. M., M., aged 26. Twelve months duration. A. T.-Slight emotional deterioration. Laziness. Occasional silly laughter. In all other respects apparently normal and ready for discharge. I. A.Splendid behaviour. Answered with un$\begin{array}{lllll}\text { No. } 17 & \ldots & 150 & \ldots & \text { Straight. } \\ \text { Av. } 56 & & 160 & \ldots & 230 \\ & & 150 & \ldots & 320 \\ & & 150 & \ldots & \text { Wink. } \\ & & & & \\ & & & & \\ & & & & \end{array}$ usual promptness, and seemed interested.

\section{DLMENTIA PARALY'ICA.}

Marked Dementia.

43. D. D., M., aged 42. Two years dura- No. 11 .. 370 .. 290 tion. A. T.-Advance $\begin{array}{llllll}390 & \ldots & 420\end{array}$ Still able to care for himself. Totally incapable of simplest labour. NoteThe first two pursuits contain one straight $350 \quad \ldots \quad 550$ line each. 
44. W. H., M., aged 48. A. T.-Extreme Mvt. Simp. R. Pend. R. dementia. Pronounced physical signs. Patient clied one week later in apoplectic seizuro. I. A.- Held without difficulty. Responses apparently slow.

$\begin{array}{lrrrr}\text { No. } 7 & \ldots & 220 & \ldots & 280 \\ \text { Av. 53 } & & 270 & \ldots & 240 \\ & & 220 & \ldots & 200 \\ & & 237 & & 240 \\ & & & \\ \text { No. } 2 & \ldots & 220 & \ldots & 241 \\ \text { Av. } 60 & & 262 & \ldots & 210 \\ & & 210 & \ldots & 220 \\ & & 210 & & \\ & & 225 & & 224 \\ \text { No. } 20 & \ldots & (370) & \ldots & 240 \\ \text { Av. } 60 & & 230 & \ldots & 310 \\ & & 240 & \ldots & 250 \\ & & 240 & \ldots & 270 \\ & & 237 & & 267\end{array}$

Less Marked Dementia.

48. J. P. E., M., agsed 60 . Eleven months duration. A. T.-Considerable dementia. Marked physical signs. Defective memory. Disorientation. Paralysis of thought. Feeling of well-boing. Some

$$
\begin{array}{rrrrr}
\text { No. } 5 & \ldots & 210 & \ldots & 210 \\
\text { Av. } 54 & & 170 & \ldots & 260 \\
& & & & 210 \\
& & & & \\
& & & & 227
\end{array}
$$
iprathy. Grandiose delusions. I. A.Tructable. Apparently good attention. Responses unusually rapid.

49. J. A., F., aged 44. One year's duration. Demented type. A. T.-Fairly pronounced dementia with severe physical signs. I. A.-Difficult to hold in position. Indifferent and poor attontion.

(b) More interested and tractable.

(b)

$\begin{array}{lllll}\text { No. } 18 & \ldots & 200 & \ldots & \text { No } \\ \text { Av. } 49 & & 260 & & \text { pursuit. } \\ & & 180 & & \\ & & 230 & \ldots & \\ & & & & \\ & & & & \end{array}$

REMISSION.

50. T. A., M., aged 43. Twolve years duration. Marked remission. Some emotional deterioration. Slightly faulty judgment. Some elation. Some spontaneity of thought. I. A.-Conduct excellont. Holpful. Read figures quickly and correctly. Marked head-movements interfered with tests 1 and 2.

$\begin{array}{lrrr}\text { Head- } & \ldots & 180 & \ldots \text { Head- } \\ \text { move- } & & 200 & \text { movements. } \\ \text { ments. } & & 200 & \\ & & & \\ & & & \\ & & \end{array}$




\section{EPILEPTICS.}

\section{All Moderate.}

51. G. L., M, aged 57. Three years duration. A. T.-Moderate dementia. Faulty memory. Impaired judgment. Delusions of infidelity. Irritability. Periodic ill-humour and violence. I. A.Splendid behaviour. Good interest and attention.

52. J. F., aged 56. Twenty-six years duration. Within last few years moderate deterioration. Faulty impressibility of memory, and faulty judgment. Increased irritability. I. A.-Good interest and apparently normal renctions.

$$
\begin{array}{crrrr}
\text { Mvt. } & \multicolumn{2}{c}{\text { Simp. l. }} & \multicolumn{2}{c}{\text { Pend. R. }} \\
\text { No. 19 } & \ldots & 330 & \ldots & 290 \\
\text { Av. } 67 & & 300 & \ldots & 250 \\
& & 290 & \ldots & 290 \\
& & 270 & \ldots & 290 \\
& & & & \\
& & & & \\
& & & &
\end{array}
$$

$\begin{array}{lllll}\text { No. } 9 & \ldots & 200 & \ldots & 210 \\ \text { Av. } 64 & & 210 & \ldots & 255 \\ & & 260 & \ldots & 200 \\ & & 240 & & \\ & & & & 222\end{array}$

53. H. O., M., aged 37. Epileptic convulsions at $2 \frac{1}{5}$ years. Mental deterioration developed at 34 . A. T.-Slight defects of judgment. Increased irritability. Periodic gloominess and stubbornness. $\begin{array}{rrrrr}\text { No. } 9 & \ldots & 190 & \ldots & 240 \\ \text { Av. } 67 & & 200 & \ldots & 240 \\ & & & \\ & & & & 210 \\ & & . & & 230\end{array}$ Slight defects of memory. I. A.Tractable. Good attention.

54. M. B., F., aged 38. Twenty-one years duration. Slight deterioration. A. T.Increased irritability. Slight defects of memory. Variable moods. I. A.Splendid behaviour. Good interest. Apparently rapid reactions.

$$
\begin{array}{lllll}
\text { No. } 8 & \ldots & 170 & \ldots & 240 \\
\text { Av. } 80 & & 200 & \ldots & 220 \\
& & 220 & \ldots & 225 \\
& & & 200 \\
& & & \\
& & & & 221
\end{array}
$$

\section{TMB3ECILES.}

Five cases of moderate imbecility gave only very scinty material. There were, however, no cases of the procox pursuit.

\section{BIBLIOGRAPHY,}

Afechanical Registration of the Eiye-Alovements.

[1] Delabarke, E. B. "A Method of Recording the Eyo-Movements," Amer. Journ. Psych., vol. ix., pp. 572-574.

[2] Huey, E. B. "Preliminary Experiments in the Physiology and Psychology of Rending," Amer. Journ. Psych., vol. ix., pp. 575-586.

[3] Idem. "On the Physiology and Psychology of Reading," Amer. Journ. Psych,, vol, xi, , pp. 283-302. 


\section{Photographic Registration of the Eye.Movements.}

[4] Cameron, IE. H., and Steece, W. M. "The Poggendorff Illusions," "Yale Studies," vol. i., No. 1, pp. 83-111.

[5] Dearbonn, A. F. "Retinal Local Sigus," Psych. Rev., vol. xi., pp. 297-307.

[6] Idem. "The Psychology of Reading," Arch. Philos, Psych., and Sci. Method, No. 4.

[7] Donge, R. "Five Types of Eye-Movement in the Horizontal Meridian Plane of the Field of Regard," Amer. Journ. Phyysiol., vol. viii., pp. 307-329.

[8] Idem. "An Exporimental Study of Visual Fixation," "Studies from the Psych. Lab. of Wesleyan Uuiv.," vol. i., Psych. Rev. Monograph Supplements, vol. viii., No. 4.

[9] Idcm and CLINr, T. S. "The Angle-Velocity of the Eye-Movements," Psych. Rev., vol. viii., pp. 145-157.

[10] Hort, E. B. " Eye-Movements during Dizziness," "Harvard Psychological Studies," vol, ii, pp. 57 fol.

[11] Jund, C. H. "The Müller-Lyer Illusion," "Yale Studies," vol. i., No. 1, pp. 55-82.

[12] 1dem. "Photographic Records of Convergence and Divergence," "Yale Psychological Studies," vol. i., No. 2, pp. 370-423, Psych. Rev. Monograph Supplement, vol. viii., No. 3.

[13] Idem and Coun'en, H. C. "The Zoelluer Illusion," "Yale Studies," vol. i., No. 1, pp. 112-140.

[14] Idcm, McAlcister, C. N., and Steece, W. M. "Introduction to a Series of Studies of Eyo-Movements by means of Kinetoscopic Photographs," Monograph Supplenient of the I'sych. Rev., vol. vii., "Yale Psychological Studies," vol. i., pp. 1-16.

[15] Mcatristra, C. N. "Fixation of Points in the Visual Field," "Yale Stuủies," vol. i., No. 1, pp. 17-54.

[16] Stratron, G. M. "Eyo-Movements and the Amsthetics of Visual Form," Philos. Stuldien, Bd. xx., S. 336. 